\title{
Medievalismos irmãos e (menos) estranhos? Para um reforço do diálogo entre as historiografias brasileira e portuguesa sobre Portugal medieval ${ }^{*}$
}

\author{
Maria de LuRdes Rosa \\ Departamento de História da Faculdade de Ciências Sociais e Humanas da \\ Universidade Nova de Lisboa - Instituto de Estudos Medievais \\ missi@oniduo.pt \\ ANDRÉ Bertoli \\ Doutorando em História medieval \\ Departamento de História da Faculdade de Ciências Sociais e Humanas da \\ Universidade Nova de Lisboa - Instituto de Estudos Medievais \\ andrelbertoli@gmail.com
}

\section{Resumo:}

$\mathrm{O}$ presente artigo tem como objectivo base oferecer uma sucinta caracterização do estado actual do medievalismo brasileiro. Num segundo momento, procura-se caracterizar brevemente a produção relativa ao Portugal medieval, destacando, quando possível, os campos em que parece possível um aprofundamento do diálogo. Por fim, apresenta-se o desafio programático da definição conjunta de inquérito(s) historiográfico(s) comuns, seja sobre as realidades medievais em Portugal, seja sobre o tema das continuidades medievais no Brasil, seja, por fim, sobre a Idade Média que se quer estudar e construir.

\section{Palavras chave:}

Historiografia sobre a Idade Média; Medievalística brasileira; Portugal medieval; Estudo de campos científicos.
Abstract:

The article has as its main goal to offer a brief characterization of the presentday Brazilian studies on the Middle Ages. Secondly, it will study in particular the scientific production on medieval Portugal made in Brazilian universities, which is likely to offer fields of cooperation between the two academies. Finally, it will propose the construction of cooperative enquiries on the Portuguese Middle Ages and on the definition of the field.

\section{Keywords:}

Historiography on the Middle Ages; Brazilian medievism; Medieval Portugal; Scientific Field studies.

"A primeira e mais alargada recolha de dados para este artigo foi feita por A. Bertoli, doutorando em História medieval da FCSH, constituindo um trabalho de seminário do Curso de doutoramento; incorporamos daí os elementos sobre as unidades de investigação e, em anexo, a recolha de resumos de teses de doutoramento; a ele se devem também muitos esclarecimentos sobre a actualidade do medievalismo universitário. O desenvolvimento da investigação e a redacção final pertencem a $M^{\text {a }}$ de Lurdes Rosa. Sublinhe-se que boa parte das informações foram obtidas online, nos sítios oficiais das instituições, devidamente sinalizadas, embora tenhamos utilizado o maior número possível de publicações papel, de natureza analítica, e tenhamos recorrido aos colegas brasileiros responsáveis por "Programas", laboratórios e congresso sobre os quais não tínhamos obtido informação fiável pelos dois modos referidos. 
À semelhança de várias tradições académicas medievalísticas, a historiografia brasileira relativa à Idade Media está em introspecção identitária ${ }^{1}$. Ao contrário da maior parte, parece devê-lo a um movimento de crescimento e de expansão, e não de crise. O sentimento não é tão claro entre os autores brasileiros, embora muitos partilhem de um optimismo quanto ao futuro. Visto deste lado do Atlântico, porém, o medievísmo brasileiro parece-nos animado por um forte dinamismo, que é sem dúvida institucional e comunga do desenvolvimento nacional, mas que se alicerça também, nos últimos anos, em numerosas reflexões sobre práticas, teorias, métodos e configurações disciplinares, que não escamoteiam, de resto, os problemas e lacunas a colmatar. Com muita - demasiada - frequência, porém, os "irmãos" medievalistas portugueses e brasileiros são antes quase "estranhos", nem sempre se conhecendo a respectiva produção. Diga-se, de entrada, que a balança do desconhecimento nos parece pesar bem mais para o lado português do que para o brasileiro; e que a influência académica de Portugal foi menos influente do que se poderia esperar, na configuração académica deste campo disciplinar, em boa parte devido às circunstâncias históricas lusas, pois apenas a partir dos anos '70 e, decisivamente, só depois da Revolução de 1974, a prática historiográfica pode começar a modernizar-se. Estamos, porém, a tempo de mudar, aproveitando - é justo referi-las - as pontes que se têm vindo a construir nos últimos anos, e alinhando definitivamente numa intenção de trabalho conjunto.

1 Referindo os principais: M. Balard (ed.), L'Histoire médiévale en France. Bilan et perspectives, Paris, Seuil, 1991; John H. Van Engen (ed.), The Past \& Future of Medieval Studies, Notre Dame, University of Notre Dame Press, 1994; Paul Freedman, Gabrielle Spiegel, "Medievalisms Old and New: The Rediscovery of Alterity in North American Medieval Studies," American Historical Review, 103 (1998), pp. 677-704; La historia medieval en España: un balance historiográfico (1968-1998): XXV Semana de Estudios Medievales, Estella, 14 a 18 de julio de 1998, Estella, Gobierno de Navarra. Depart. Educación y cultura, 1999; Alain Guerreau, L'avenir d'un passé incertain: quelle histoire du Moyen-âge au XXIe siècle?, Paris, Seuil, 2001; J. Hamesse (ed.), Bilan et perspectives des études médiévales en Europe (1993-1998), Louvain-la-Neuve, 2003; Jean-Claude Schmitt, Otto G. Oexle (eds.), Les tendances actuelle de l'Histoire du Moyen-âge en France et en Allemagne, Paris, Publ de la Sorbonne, 2003; C. Stephen Jaeger (ed.), "The state of medieval studies", The Journal of English and Germanic Philology, vol. 105, $\mathrm{n}^{\circ} 1$ (Janeiro 2006); Alan Deyermond (ed.), A century of British medieval studies, Londres, British Academy, 2007. Para Portugal veja-se o recente balanço global de Judite A. Gonçalves de Freitas, "La Médiévistique au Portugal (1970-2005): genèses, héritages et innovations", in Eliana Magnani (ed.), Le Moyen Âge vu d'ailleurs: voix croisées d'Amérique latine et d'Europe, Dijon, EUD, 2010, pp. 151-174, que refere praticamente todos os balanços anteriores. O IEM (FCSH-UNL) encontra-se a preparar uma obra colectiva sobre a historiografia relativa a Portugal medieval, c. 1950-2010, cuja publicação se estima para final de 2011. 
O presente artigo tem como objectivo base oferecer uma breve caracterização do estado actual do medievalismo brasileiro, usufruindo de um conjunto de excelentes estudos e úteis instrumentos de trabalho elaborados pelos colegas brasileiros. Apenas a partir destes nos atrevemos a tal, sem que queiramos sair de um registo essencialmente informativo. Tentaremos, num segundo momento, caracterizar brevemente a produção relativa ao Portugal medieval, destacando, quando possível, alguns campos em que o diálogo entre os dois grupos de estudiosos do mesmo grande assunto nos surge como particularmente fecundo, seja em termos de conhecimento acumulado, seja de novas perspectivas. Terminaremos com um desafio programático: porque não definir em conjunto inquérito(s) historiográfico(s) comuns, seja sobre as realidades medievais em Portugal, seja sobre o interessantíssimo tema das continuidades medievais no Brasil, seja, por fim e no fundo, sobre que Idade Média queremos estudar e construir?

Este último ponto leva-nos a uma ideia de base, que se impõe sublinhar fortemente, antes de prosseguir. De modo algum defendemos que o quadro de estudo da época medieval tenha de ser o nacional ou o de "raiz colonial". Como referiremos, um dos grandes avanços do medievalismo brasileiro, que a nosso ver só fortalece a sua identidade científica, é a libertação da obrigação do estudo de Portugal medieval como "país de origem”. Nada fácil - é preciso dizê-lo, pois a legitimação do campo disciplinar pelo estudo das "origens coloniais" é quase "natural" nizante e, ainda, porque se fez segundo um processo de discussão da razão de estudo da Idade Média que foi rico em ideias - do estudo das permanências à teorização das continuidades e rupturas, chegando à ideia de que se estuda Idade Média pelo seu interesse científico-cultural intrínseco ${ }^{3}$. É sem hesitação que afirmamos que este é um dos debates em que Portugal pode beneficiar claramente da reflexão brasileira, habituados que estamos a estudar, "naturalmente" - sem o questionar a fundo, portanto - a "Idade Média nacional". Para além das barreiras artificiais, em termos de problemáticas, este hábito faz com que se prolonguem, de forma difusa e pouco consciente, relações de natureza verdadeiramente "colonial" dentro da historiografia europeia. Ao definir desta forma problemáticas do "Portugal medieval",

2 Eliana Magnani,'Entre politique et disciplinaire: les études médiévales en Europe et en Amérique latine", p. 10, in Le Moyen Âge vu d'ailleurs, pp. 7-14.

3 Hilário Franco Júnior, Leandro Duarte Rust, Mário Jorge da Motta Bastos, "Historiographie et médiévistique brésilienne: une approche d'ensemble", p. 51, in Le Moyen Âge vu d'ailleurs, pp. 39-52; e cfr. infra, pp. 22 ss. 
trabalhamos com um quadro de referência de uma "Idade média" geral, ou a-nacional, mas que é de facto, as mais das vezes, a Idade Média da Europa central e do Norte, que raramente se define como "Idade Média nacional" pelos países que a praticam - e que funcionam assim como "metrópole" impositora dos seus ritmos ao passado das "colónias".

Esclarecida pois a ruptura total com modelos nacionalistas e/ou coloniais, é porém forçoso dizer que existem razões de monta para que trabalhemos a partir dos trabalhos sobre um mesmo passado, sendo isto entendido como um primeiro passo num processo de aproximação científica. Em primeiro lugar, razões do foro prático: desde logo, as afinidades linguísticas e culturais, que facilitam enormemente o diálogo e que agilizam também, em particular, a especialização que os estudos medievais impõem, em termos de filologia e paleografia; e é efectiva a existência de um significativo número de medievalistas brasileiros com interesse na Idade Média portuguesa. Em segundo lugar, razões de âmbito científico: desde logo, a possibilidade de interrogarmos especificidades, olhadas não como uma retroprojecção anacrónica da "nação", mas sim como originadas num complexo sócio-político que efectivamente existiu, com diferenças em relação a outros, que importa teorizar, interrogar e construir; depois, a hipótese da construção de identidades de medievalistas - enfim, de historiadores mais adequadas ao século XXI, em que as relações tradicionais dos saberes, em termos de centros de produção Norte-Sul, Europa e extra-Europa, estão em completa mutação - positiva e enriquecedora, quanto a nós - e, em qualquer caso, imparável. A relação entre as duas historiografias não poderá nunca ser, nestes moldes, colonial... Até porque a medievalistica portuguesa é um campo científico e institucional de média consistência, em comparação a locais de produção mais fortes, e que se encontra actualmente também num momento charneira. A capacidade de competição científica internacional tem forçosamente de passar, por um lado, por sinergias institucionais e pela modificação dos modos de trabalho tradicionais; por outro, pelo reforço teórico e pela capacidade de definir inquéritos solidamente ancorados nas mais modernas perspectivas.

\section{Identificação de um medievalismo}

\subsection{Uma tradição de escritos de auto-caracterização e de reflexão}

O mais rápido relancear de olhos pela produção historiográfica dos medievalistas brasileiros dos últimos quinze anos, permite apreender a extensão do processo em curso. É legítimo afirmar que estamos em presença de um notável - e nem sempre comum - trabalho de auto-identificação científica, 
que promete, pela extensão e profundidade, criar frutos sólidos no futuro próximo. Os medievalistas brasileiros têm interrogado a razão de ser da sua existência, promovido levantamentos sobre os seus materiais de trabalho, investigado o tipo de formação científica que receberam e ministram, mapeado as condições institucionais da sua investigação, apontado os problemas da reprodução académica vs criação de escolas de investigação, interrogado fontes e conceitos, celebrado inúmeras reuniões nacionais e internacionais sobre o campo científico a que se dedicam. Nas linhas que se seguem, tentaremos apresentar as linhas principais deste processo.

Podemos localizar em meados dos anos '90 o início de uma reflexão aprofundada e continuada sobre o seu campo de estudos, por parte dos medievalistas brasileiros. Como noutras tradições científicas, esta exigência de auto-reflexão dá-se após e durante um período de crescimento relevante. A periodização estabelecida por Vanessa Asfora, E. Aubert e G. Castanho coloca os meados de " 90 como o culminar da primeira grande fase de crescimento e reforma da universidade brasileira, iniciada em 1968; marcante foi, nesse período, a regulamentação a nível federal dos estudos de pós-graduação e a criação de programas a este nível nas universidades federais. A partir de então, o crescimento acentua-se e, em termos de formação, passa-se dos mestrados aos doutoramentos ${ }^{4}$. E data também de meados da década de 90 a criação da ABREM, associação a que coube um papel fundamental na formação de uma rede de debate e trabalho, que continua em plena actividade 5 . É justo realçar que existiam núcleos de investigação e programas de pós-graduação em História medieval antes da fundação da ABREM, como adiante se verá, e que eles tiveram um papel fundamental na consolidação do estudo científico da Idade Média. De resto, muito dos seus membros estão por detrás da criação da ABREM, deste modo se compreendendo também o dinamismo da associação.

Assim, depois de um pioneiro estado da questão, em 1994, por M. G. Pedrero Sanchez ${ }^{6}$, em que a consciência das carências e dificuldades balanceia com um moderado optimismo, é nos Encontros da ABREM que vemos desenvolver-se

4 Seguimos aqui o excelente estudo de Wanessa Asfora, Eduardo Henrik Aubert e Gabriel de Carvalho Godoy Castanho, "L'Histoire médiévale au Brésil. Structure d'un champ disciplinaire", p. 93, in Le Moyen Âge vue d'ailleurs: voix croisées, pp. 55-113.

5 Cfr. www.abrem.org.br/. O relevo dado à ABREM é consensual na bibliografia; veja-se por ex. "Translatio studii". A história medieval no Brasil", pp. 163-165, Signum, 10 (2008), pp. 163-188.

6 M. G. Pedrero Sanchez, "Los estudios medievales en Brasil”, Medievalismo 4/4 (1994), 223-228. 
a interrogação disciplinar, em crescendo, e incidindo quer sobre os conteúdos quer sobre a razão de ser do campo científico ${ }^{7}$. A necessidade concomitante de inventariar os materiais empíricos disponíveis nas bibliotecas brasileiras deu lugar a um empreendimento colectivo de monta, também a partir da ABREM, cujo primeiro volume surgiu ainda antes do final da década ${ }^{8}$. Há claramente uma preocupação de dotar o medievalismo brasileiro de um roteiro de trabalho possível dentro das fronteiras do País, pondo em relevo o que estas tinham de disponível para uma época da qual, à partida, poucos sinais existiriam no Brasil. $\mathrm{O}$ trabalho realizado tem o enorme mérito de provar que existe material e de optimizar os recursos. Boa parte das colecções de fontes impressas identificadas é hoje em dia de difícil, senão impossível aquisição, e pelo seu carácter especializado, a poucos serviriam que não aos medievalistas.

A primeira década do século XXI corresponde a uma rapidíssima projecção internacional do medievalismo brasileiro e a uma igualmente notável dinâmica de reflexão interna. $\mathrm{O}$ ano de 2002 assiste à publicação de um artigo global sobre os estudos medievais numa renomada revista espanhola de estudos medievais e à realização, em Auxerre, do primeiro encontro do Programa "Le Moyen âge vu d'ailleurs", organizado pelo Centre d'Études Médiévales d'Auxerre e pela "Unité Mixte de Recherche" 5594 ARTeHis (Archéologie, Terre, Histoire, Sociétés $)^{9}$, com o apoio de um conjunto alargado de instituições universitárias e de apoio à investigação francesas, brasileiras e $\operatorname{argentinas~}^{10}$. O "Programa"

7 Mongelli, Lênia Márcia, “A ABREM e os estudos medievais no Brasil”, in José Rivair Macedo (ed.) Atas do II Encontro Internacional de Estudos Medievais, Revista do Instituto de Filosofia e Ciências Humanas da Universidade Federal do Rio Grande do Sul, vol. 21, no. 1 (1998) t. I, pp. 465-473; Leão, Angela Vaz, "Os estudos medievais na atualidade brasileira: região Sudeste”, in $\mathrm{M}^{\mathrm{a}}$ do Amparo Tavares Maleval (ed.), Atas do III Encontro Internacional de Estudos Medievais, pp. 138-145, Rio de Janeiro, Ágora da Ilha, 2001; Mongelli, Lênia Márcia, “A quem se destinam os estudos medievais no Brasil?", Atas do III Encontro Internacional, pp. 146-154; Ribeiro, Maria Eurydice de Barros, "Os estudos medievais no Distrito Federal", Atas do III Encontro Internacional, pp. 155-158; Santos, Maria do Carmo Parente, "Pesquisas medievalistas centralizadas em universidades cariocas", Atas do III Encontro Internacional, pp. 159-161.

8 Lênia Márcia Mongelli (org.), Fontes primárias da Idade Média: séculos V-XV, vols. 1-2, São Paulo, ABREM; Cotia, Íbis, 1999; vol 3, São Paulo, ABREM; Cotia, Íbis, 2005. O resultado do levantamento feito no Rio Grande do Sul foi organizado por José Rivair Macedo e está disponível em: http://www.gtestudosmedievais.ufrgs.br/fontes_primarias.pdf.

9 Rede de investigação tutelada pela Université de Bourgogne, o CNRS e o Ministério da Cultura francês.

${ }^{10}$ Sobre o Programa pode-se encontrar informação completa e sequencial (programa e recensão de cada encontro, balanços globais e publicação de resultados) no Bulletin du Centre d'Études Médiévales d'Auxerre, publicação em linha (http://cem.revues.org/index11439.html). 
constou de mais três encontros, respectivamente em 2003 (S. Paulo), 2005 (Madrid) e Buenos Aires (2006) e gozou sempre da mais alta qualidade, em termos de participantes e de publicação de resultados. Dele saíram dois livros em papel ${ }^{11} \mathrm{e}$ uma publicação electrónica ${ }^{12}$, para além de artigos publicados em diversos locais, sobretudo no Bulletin du Centre d'Études Médiévales d'Auxerre. No primeiro Encontro, Hilário Franco Jr. e Mário J. da Motta Bastos apresentaram uma comunicação sobre a medievalística brasileira que a caracterizava globalmente, apresentando as suas genealogias académica, pessoal e científica, e apontando também caminhos de futuro ${ }^{13}$.

Os anos seguintes assistem a uma continuidade da realização de balanços historiográficos por vezes publicados fora do País - o que revela a capacidade de projecção exterior dos medievalistas brasileiros e o interesse por eles existente em algumas redes universitárias do Velho Mundo - globais ${ }^{14}$ ou

Cfr., por todos, e com indicação da bibliografia sobre o Programa, Eliana Magnani, "Avant propos", in "Le Moyen Âge vu d'ailleurs", Bulletin du Centre d'Études Médiévales d'Auxerre h.s n 2 (2008) (http://cem.revues.org/index10652.html).

${ }^{11}$ Eliana Magnani, Hilário Franco Jr., Flávio de Campos (orgs.), Le Moyen Âge vu d'ailleurs II. Historiografia e pesquisas recentes, São Paulo, Instituto de Estudos Avançados da Universidade de São Paulo, Setembro 2004 (reúne as comunicações da sessão de 2003 e aguarda uma edição comercial definitiva); e Eliana Magnani (ed.), Le Moyen Âge vu d'ailleurs (balanços historiográficos).

12 "Le Moyen Âge vu d'ailleurs", Bulletin du Centre d'Études Médiévales d'Auxerre h.s $\mathrm{n}^{\circ} 2$ (2008), que reúne a maior parte das contribuições, distribuídas por seis temas (Eliana Magnani, “Avant propos").

${ }^{13}$ Hilário Franco Júnior, Mário Jorge da Motta Bastos, «L’histoire du Moyen Âge au Brésil», Bulletin du centre d'études médiévales d'Auxerre, 7 (2003) (http://cem.revues.org/index3322. html); uma segunda versão reformulada, com Leandro Duarte Rust, é "Historiographie et médiévistique brésilienne", acima referida, e que integra também elementos de um outro estudo de dois dos autores (Leandro Duarte Rust, Mário Jorge da Motta Bastos, "Translatio studii”). Na sua versão final, este é um dos artigos mais ensaísticos e programáticos do conjunto de textos evocados neste artigo, por comparação com outros mais na área da sociologia académica e do estudo da produção cientifica.

${ }^{14}$ José Rivair Macedo, "Os estudos medievais no Brasil: tentativa de síntese”, Reti Medievali - Rivista, VII, 2006, 1, (www.retimedievali.it); Carlos Roberto Figueiredo Nogueira, "Velhos temas, novos objectos: os estudos medievais no Brasil de hoje" in O. Coggiola (dir.), Caminhos da História, S. Paulo, 2006, pp. 29-3; Maria Filomena Coelho, "Breves reflexões acerca da História medieval no Brasil", in Andréia Cristina Silva, Leila Rodrigues Silva (org.), Atas da VI Semana de Estudos medievais, Rio de Janeiro, PEM, 2006, pp . 29-33 (disponível em http:// www.pem.ifcs.ufrj.br/AtasVISem.pdf); Almeida, Ana Carolina, Amaral, C. de O., «O Ocidente Medieval segundo a historiografia brasileira», Medievalista online, ano 4, n. 4, (2008), pp. 1-41; Leandro Duarte Rust, Mário Jorge da Motta Bastos, “'Translatio studii’ . A história medieval no Brasil”, Signum, 10, pp. 163-188, 2008; Vieira, Yara Frateschi. "Os Estudos Medievais no Brasil: peso (ou leveza) de uma tradição", in Roberto Pontes e Elizabeth Dias Martins (org.), Anais do 
específicos ${ }^{15}$. Verifica-se ainda a elaboração de três estudos sobre as condições institucionais de realização da investigação, baseados em inquéritos, análises estatísticas e apresentação das estruturas de financiamento e enquadramento ${ }^{16}$. A publicação actualizada de um destes artigos, em 2010, no volume Le Moyen âge vu d'ailleurs, apõe-lhe o significativo título "a estrutura de um campo disciplinar"17. A par deste tipo de elementos de auto-identificação e de detecção de problemas a resolver, é publicado um valioso instrumento de trabalho - o Catálogo de dissertações e teses de temática medieval, nos campos da Filosofia, história e Letras, organizado pelo Professor José Rivair de Macedo $(2003)^{18}$. Não é pois de estranhar que, entre 2007 e 2009, tenham sido anunciados dois projectos de "mapeamento" sistemático e aprofundado da produção medievalística brasileira recente, bem como "uma análise crítica dos rumos e perspectivas dos estudos sobre a Idade Média realizados no Brasil"19.

VII Encontro Internacional de Estudos Medievais - Idade Média: permanências, atualização, residualidade, Fortaleza/Rio de Janeiro, UFC/ABREM, 2009, pp. 75-85; Marcelo Candido da Silva, "Les études médiévales au Brésil", in ciham.ish-lyon.cnrs.fr/Brazil.html - [s.d., final Dez. 2000].

${ }^{15}$ Leila Rodrigues da Silva, Andréia Cristina Lopes Frazão da Silva, “Os Estudos Medievais no Brasil e a Internet: uma análise do uso dos recursos virtuais na produção medievalista (1995 a 2006)", História, imagem e narrativas, No 4, ano 2 (Abril/2007) (http://www.historiaimagem. com.br).

${ }^{16}$ Eliana Magani, Néri Barros Almeida (et al), "Être historien du Moyen Âge en Amérique latine au début du XXIe. siècle: enquête", in SHMESP (ed.), Être historien du Moyen-Âge au XXIe. siècle, Paris, Publ. de la Sorbonne, 2008,pp.71-92; Néri de Barros Almeida, «La formation des médiévistes dans le Brésil contemporain: bilans et perspectives (1985-2007)», Bulletin du centre d'études médiévales d'Auxerre (http://cem.revues.org/index6652.html); Wanessa Colares Asfora, Eduardo Henrik Aubert e Gabriel de Carvalho Godoy Castanho, «Faire l'histoire du Moyen Âge au Brésil: fondements, structures, développements», Bulletin du centre d'études médiévales d'Auxerre, 12 (2008) (http://cem.revues.org/index6602.html).

${ }^{17}$ Wanessa Colares Asfora, Eduardo Henrik Aubert et Gabriel de Carvalho Godoy Castanho, "L'Histoire médíévale au Brésil".

${ }^{18}$ Macedo, J. R. (Org.), Os estudos medievais no Brasil. Catálogo de dissertações e teses Filosofia, História e Letras (1990-2002), Porto Alegre, EDUFRGS, 2003 (disponível online no site da ABREM).

${ }^{19}$ A primeiraexpressão é dos autores da "Apresentação" à edição dos Anais do I Encontro de Estudos Medievais do Rio Grande do Sul, na revista Aedos, vol. 2, n 2 (2009) (Igor S. Teixeira, Nilton Mullet Pereira, Cybele Crossetti de Almeida, Rodrigo M. Alberto). O colóquio teve lugar em Junho de 2009 na Universidade Federal de Rio Grande do Sul. A segunda provém da apresentação do projecto do LEME (USP), "Produção científica e progressão institucional na pesquisa sobre a Idade Média no Brasil (2002-2007)" no site da instituição (http://www.usp.br/ leme/, separador "projectos"). 


\subsection{Um medievalismo de associações e de debates}

As publicações analisadas resultam, com frequência, de reuniões científicas. Esta é uma outra característica que merece realce. Toda a década de ' 90 , e ainda mais a seguinte, foram atravessadas por reuniões periódicas dos grupos medievalistas ${ }^{20}$, das quais têm quase sempre resultado actas, e que não dão mostras de abrandar. O PEM da UFRJ teve o seu primeiro encontro em 1991, celebrando mais dois com cadência bienal; depois de um interregno de poucos anos, a Semana de Estudos Medievais celebrou em 2009 a sua VIII edição ${ }^{21}$. A ABREM, por seu turno, tem mantido a mesma regularidade de reuniões internacionais, prevendo-se para o ano de 2011 o IX Encontro Internacional de Estudos Medievais ${ }^{22}$; e realiza ainda diversos encontros de âmbito regional e estadual ${ }^{23}$. O LEME, da USP, caracteriza-se pela realização de encontros de diversos tipos, em geral com a participação de destacados medievalistas franceses (em 2008 saliente-se o «Colóquio Internacional sobre Estudos de História Medieval e Ciências Humanas, "Porquê estudar a Idade Média no século XXI?"»), pela realização de "seminários de pesquisa" mensais e outros tipos de reunião científica ${ }^{24}$. Uma cadência certa e muito frequente tem sido conseguida para os "Encontros luso-brasileiros de História medieval", organizados por diferentes instituições universitárias e académicas, desde 2006. Já tiveram lugar seis destas reuniões, ora em Portugal, ora no Brasil, tendo vindo a crescer em dimensão e apresentando temáticas e abrangências temporais diversificadas ${ }^{25}$.

${ }^{20}$ Informação mais detalhada sobre eles poderá ver-se infra, pp. 10 ss.

${ }^{21} \mathrm{http}: / /$ www.pem.ifcs.ufrj.br/eventos.htm.

${ }^{22}$ Acta da VII Assembléia Geral da ABREM, de 14 de Agosto de 2009, disponível no site da associação (http://www.abrem.org.br/atas_assembleia.php).

${ }^{23}$ Segundo informações em idem.

${ }^{24}$ Informações constantes do site da instituição - http://www.usp.br/leme/.

${ }^{25}$ I - 2006 (org. pelo PEM-Unb, constituindo a «VI Semana de Estudos medievais» deste laboratório, publ. - Instituições, cultura e poder na Idade Média Ibérica. Atas do I Encontro Luso-brasileiro de História medieval / $6^{a}$ Semana de Estudos Medievais, Brasília, UNB, 2006); II, 2007 - «Raízes medievais do Brasil moderno» (Manuela Mendonça (org.), Raízes medievais do Brasil moderno, Lisboa, Centro de História da UL; Centro de História da Cultura da FL-UC, Academia Portuguesa da História, 2008); III, 2008 - «Monarquia e sociedade no Portugal medieval» (org. pelo GEMPO e Cátedra Jaime Cortesão; Carlos Roberto F. Nogueira (ed.), O Portugal Medieval. Monarquia e Sociedade, São Paulo: Alameda, 2010); IV, 2009 - «Relações entre o Estado e a Igreja», Coimbra; V, 2010 - «A Idade Média portuguesa e o Brasil: reminiscências, transformações, ressignificações» (informações em http://www.anpuh-rs.org.br/informativo/view?ID_INFORMATIVO=1171). 
O Pem-UnB ${ }^{26}$ conta também com uma longa tradição de encontros, com actas publicadas, tendo realizado em 2009 a sua "VII Semana de Estudos medievais"27. O Scriptorium e o «Grupo de Trabalho de Estudos Medievais da Associação Nacional de História - Núcleo Rio Grande do Sul» (GTRGS) ${ }^{28}$ juntaram-se mais recentemente a esta tendência, acertando o passo com a realização de dois importantes colóquios, respectivamente "Ler, escrever e narrar na Idade Média" (2009) ${ }^{29}$ e o I Encontro Estadual de Estudos Medievais" ${ }^{30}$. Esta última estrutura remete para uma outra influentíssima organização com papel relevante neste âmbito, a ANPUH (Associação Nacional de História), que acolhe "grupos de trabalho" como o referido (os de temática medieval encontram-se nas secções regionais) e inclui, no Encontro bienal, simpósios temáticos de temática medieval ${ }^{31}$. De existência mais recente, oTranslatio Studii - Núcleo Dimensões do Medievo (História, Língua e Filosofia), da UFF, realizou em 2008 o seu primeiro encontro e em 2010 o segundo ${ }^{32}$. Já no Maranhão, o laboratório Mnemosine tem promovido encontros de História Antiga e medieval (nacional e internacional).

\subsection{Um medievalismo em expansão institucional (formações pós-gradua- das e centros de investigação)}

Em termos de estruturas de ensino, são os "Programas de Pós-Graduação", em História e noutras áreas das Ciências Sociais e Humanas, os enquadramentos da elaboração de teses de mestrado e doutoramento. Estes "Programas" são avaliados anual e trienalmente pela Capes (Coordenação de aperfeiçoamento de pessoal de nível superior), e no site desta instituição, bem como no das

${ }^{26}$ O PEM - UnB não tem site, o que dificulta a recolha de informação sobre ele. Agradecemos penhoradamente à Prof. Maria Eurydice Ribeiro, fundadora e actual co-coord. do laboratório, as informações prestadas, bem como às Profs. M. ${ }^{a}$ Filomena Coelho (co-coordenadora desde 2009) e Maria Helena Cruz Coelho da Faculdade de Letras da Universidade de Coimbra. Obtivemos a informação de que o site estará em breve actualizado e disponível.

${ }^{27} \mathrm{http}: / /$ www.semanadeestudosmedievais.rg3.net.

${ }^{28} \mathrm{http}: / / \mathrm{www} . \mathrm{gtes}$ tudosmedievais.ufrgs.br/.

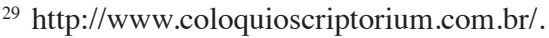

${ }^{30} \mathrm{http}$ ://www.gtestudosmedievais.ufrgs.br/eeem.htm (disponível online: http://seer.ufrgs.br/ aedos/issue/view/800).

${ }^{31} \mathrm{http}: / /$ www.anpuh.org/.

${ }^{32}$ Do primeiro, que foi realizado em simultâneo com o II Encontro Regional da ABREMRJ, resultou o livro Andréia Cristina Silva (et al.) (org.), Idade Média: abordagens interdisciplinares, Rio de Janeiro, Pem, 2009), para o segundo, de Novembro de 2010, cfr o site http:// congressotempusfugit.wordpress.com/. 
diferentes universidades, podem encontrar-se elementos sobre eles ${ }^{33}$. No âmbito deste artigo, e também porque há oscilações anuais, seria difícil apresentar todos os "PPG" que incluem os estudos medievais. Remetemos para os trabalhos que apresentam as principais estruturas de ensino universitário brasileiras deste âmbito $^{34}$, e tentaremos, no ponto seguinte deste trabalho, caracterizar a produção de dissertações relativas a Portugal medieval.

Por fim, cumpre referir as estruturas de investigação, inseridas nas universidades ${ }^{35}$. Iniciamos pelo Scriptorium - Laboratório de Estudos Medievais e Ibéricos,$^{36}$ fundado em 1988 pela Professora Doutora Vânia Leite Froes ${ }^{37}$ actual coordenadora - na Universidade Federal Fluminense (UFF). Com mais de duas décadas de existência, este grupo originou-se a partir do Grupo de Estudos Medievais. Hoje, muitos dos medievalistas formados neste Laboratório actuam em outras universidades brasileiras, aumentando a sua área de influência. Este núcleo possui cinco linhas de pesquisa: 1 - Cultura e Estética Medieval; 2 - Economia e Sociedade Medieval; 3 - História e Identidades na Idade Média; 4 - Imaginário e Poder Político na Idade Média; 5 - Produção Historiográfica e Ensino de História na Idade Média ${ }^{38}$.

No estado do Rio de Janeiro ainda há outro importante grupo de pesquisa em História Medieval, mas com sede na Universidade Federal do Rio de Janeiro (UFRJ). O Programa de Estudos Medievais (PEM) ${ }^{39}$ foi criado em 1991, com uma proposta interdisciplinar. O PEM tem como objectivos estimular o intercâmbio entre medievalistas brasileiros e estrangeiros; formar novos pesquisadores; promover discussões académicas; identificar, preservar e divulgar acervos de fontes relativas à Idade Média; produzir material didáctico

${ }^{33}$ http://www.capes.gov.br/avaliacao/cursos-recomendados-e-reconhecidos.

${ }^{34}$ Wanessa Asfora, Eduardo Henrik Aubert e Gabriel de Carvalho Godoy Castanho, "L’Histoire médiévale au Brésil"; Hilário Franco Júnior, Leandro Duarte Rust, Mário Jorge da Motta Bastos, "Historiographie et médiévistique"; Neri de Barros Almeida, "La formation des médiévistes dans le Brésil contemporain".

${ }^{35}$ Para além dos sites das instituições e em especial quando estas não os têm, consultámos o "Diretório de Grupos de Pesquisa" do CNPq (http://www.cnpq.br/gpesq/apresentacao.htm).

${ }^{36} \mathrm{http}: / /$ dgp.cnpq.br/buscaoperacional/detalhegrupo.jsp?grupo=0005705HYAJR0U; http:// www.proac.uff.br/scriptorium/.

${ }^{37}$ Currículo Lattes: http://buscatextual.cnpq.br/buscatextual/visualizacv.jsp?id=K4783972U1.

${ }^{38} \mathrm{http}$ ://www.proac.uff.br/scriptorium/index.php?option=com_content\&task=view\&id=27 \&Itemid=69.

${ }^{39} \mathrm{http}$ //dgp.cnpq.br/buscaoperacional/detalhegrupo.jsp?grupo=0202705MW58W1S; http:// www.pem.ifcs.ufrj.br/. 
e patrocinar actividades de extensão universitária. ${ }^{40}$ Actualmente, este grupo é coordenado pelas professoras Doutora Andréia Cristina Lopes Frazão da Silva ${ }^{41}$ e Doutora Leila Rodrigues da Silva. ${ }^{42}$ Dentre as linhas de pesquisa do PEM, estão: 1 - A organização institucional e a produção intelectual eclesiásticas no medievo; 2 - A hagiografia e o fenómeno da santidade no medievo, 3 - As dinâmicas legislativa e jurídica medievais.

Já o Laboratório de Estudos Medievais (LEME) ${ }^{43}$, activo desde 2005 , congrega professores, pesquisadores e estudantes dos Departamentos de História da Universidade de São Paulo (USP), da Universidade Estadual de Campinas (UNICAMP), da Universidade Federal de Minas Gerais (UFMG) e da Universidade Federal de São Paulo (UNIFESP). Este laboratório foi formado com o objectivo de desenvolver estudos e actividades na área de História Medieval, bem como estabelecer interlocução com historiadores e centros de estudos estrangeiros. Actualmente há quatro linhas de pesquisa: 1 - A «regio religio» em questão; 2 - Escrita e poder; 3 - Monarquia e Justiça na Idade Média; 4 - Paz e Violência na Alta Idade Média; 5 - Paz e Violência na Era Gregoriana. Além dos seus membros, o LEME conta com colaboradores de diversas instituições estrangeiras. O actual coordenador é o Professor Doutor Marcelo Cândido da Silva. ${ }^{44}$

Outro núcleo de pesquisa na USP, mas com a especificidade de se concentrar sobre temas medievais portugueses, é o Grupo de Estudos Medievais Portugueses (GEMPO) ${ }^{45}$. O GEMPO, ligado a Cátedra Jaime Cortesão da USP, é coordenado pelo Professor Doutor Carlos Roberto Figueiredo Nogueira ${ }^{46}$ e foi fundado em 2006. Este grupo congrega professores e pesquisadores que se dedicam ao estudo do poder real, da monarquia e das relações de solidariedade em Portugal medieval. No Brasil, trabalha em parceria com a UFRJ, a UNB, a UFRGS e a UNIFESP e, em Portugal, com a Universidade de Coimbra e a Universidade de Lisboa. ${ }^{47} \mathrm{O}$ grupo tem duas linhas de pesquisa: 1 - "Poder e

${ }^{40} \mathrm{http} / / /$ www.pem.ifcs.ufrj.br/pem.htm.

${ }^{41}$ Currículo Lattes: http://buscatextual.cnpq.br/buscatextual/visualizacv.jsp?id=K4785987J3 .

${ }^{42}$ Currículo Lattes: http://buscatextual.cnpq.br/buscatextual/visualizacv.jsp?id=K4721620E3.

${ }^{43} \mathrm{http}$ ://dgp.cnpq.br/buscaoperacional/detalhegrupo.jsp?grupo=0067705LS2ENU4; http:// www.usp.br/leme/.

${ }^{44}$ Currículo Lattes: http://buscatextual.cnpq.br/buscatextual/visualizacv.jsp?id=K4761760P0.

${ }^{45} \mathrm{http}: / /$ www.fflch.usp.br/cjc/gempo/index.htm.

${ }^{46}$ Currículo Lattes: http://buscatextual.cnpq.br/buscatextual/visualizacv.jsp?id=K4797365D1.

${ }^{47} \mathrm{http}: / /$ www.fflch.usp.br/cjc/gempo/index.htm. 
relações de solidariedade em Portugal medieval"; 2 - "Monarquia e Ordens Militares no Portugal Medieval (sécs. XIV-XVI)". ${ }^{48}$

Em outra instituição de ensino superior do estado de São Paulo, a Universidade Estadual Paulista (UNESP), há o Núcleo de Estudos Antigos e Medievais (NEAM).$^{49}$ O NEAM, criado em 1999, reúne pesquisadores de diversas universidades, principalmente dos campi da UNESP em Franca e Assis. Os trabalhos desenvolvidos na UNESP abordam diferentes contextos, desde a produção sobre a Alta Idade Média na UNESP/Assis até trabalhos sobre História Medieval Portuguesa na UNESP/Franca. A única linha de pesquisa deste grupo é intitulada 1 - Religiões e Visões de Mundo.

Entre os grupos mais antigos conta-se ainda o PEM-UnB (Universidade de Brasília), fundado em inícios da década de '90. Os objectivos então definidos foram: reunir projectos que tratassem do Ocidente medieval, promovendo e divulgando a pesquisa; promover o estudo da longa duração, relacionando a história do Brasil com a de Portugal; promover o levantamento de fontes primárias impressas e manuscritas existentes no Distrito Federal. Em termos de linhas de pesquisa, criaram-se duas, "História da cultura medieval" que reuniu projectos sobre a representação do espaço na Idade Média, em especial na cartografia medieval (dir. Maria Eurydice Ribeiro) e "História política da Idade Média" (dir. Celso Fonseca) ${ }^{50}$.

No estado do Rio Grande do Sul há o Grupo de Trabalho (GT) de Estudos Medievais,$^{51}$ fundado em 1999, em Porto Alegre. Este reúne investigadores, estudantes e professores das universidades do estado de origem, interessados em História, Literatura e Filosofia da Idade Média. O grupo é filiado na Associação Nacional de História (ANPUH), exercendo suas actividades na ANPUH Rio Grande do Sul. ${ }^{52}$

Em Curitiba, capital do Paraná, formou-se o Núcleo de Estudos Mediterrânicos (NEMED) ${ }^{53}$. O NEMED, criado em 2002 no Departamento de História da Universidade Federal do Paraná (UFPR), é coordenado pelos professores Renan Friguetto ${ }^{54}$ e Fátima Regina Fernandes.$^{55}$ Dedicado, sobretudo, ao estudo

${ }^{48} \mathrm{http} / / /$ www.fflch.usp.br/cjc/gempo/linhas.htm.

${ }^{49} \mathrm{http}: / / \mathrm{dgp} . \mathrm{cnpq} . \mathrm{br} / \mathrm{buscaoperacional/detalhegrupo.jsp?grupo=03307059H1QHUN}$.

${ }^{50}$ Cfr. supra, nt. 26.

${ }^{51} \mathrm{http}: / / \mathrm{www} . g t e s t u d o s m e d i e v a i s . u f r g s . b r /$.

$52 \mathrm{http}: / /$ www.anpuh-rs.org.br/.

${ }^{53} \mathrm{http}$ ://dgp.cnpq.br/buscaoperacional/detalhegrupo.jsp?grupo=0103705AHQ2CJT; http:// www.nemed.he.com.br/.

${ }^{54}$ Currículo Lattes: http://buscatextual.cnpq.br/buscatextual/visualizacv.jsp?id=K4782032E7.

${ }^{55}$ Currículo Lattes: http://buscatextual.cnpq.br/buscatextual/visualizacv.jsp?id=K4782153Y3. 
do Mundo Mediterrânico desde a Antiguidade Clássica até o século XVI, o núcleo conta com pesquisadores em várias universidades brasileiras e no exterior (Alemanha, Argentina e Chile). As linhas de pesquisa deste grupo são: 1 - As concepções dos poderes imperial e régio na Antiguidade Tardia Mediterrânica; 2 - As crónicas da civilização medieval mediterrânica; 3 - Instituições, poderes e sociedade na medievalidade.

A seguir, citaremos rapidamente mais alguns grupos de História Medieval fundados nos últimos dez anos e ainda em fase de consolidação. Muitos deles nasceram da irradiação da influência dos mais antigos, nomeadamente do Scriptorium, do PEM-UFRJ e do GEMPO. No estado do Espírito Santo há dois grupos de pesquisa vinculados à Universidade Federal do Espírito Santo (UFES), Estudos Filosóficos em História Antiga e Medieval ${ }^{56}$ (formado em 2007) e A Violência no Mundo Antigo e Medieval ${ }^{57}$ (formado em 2008), ambos coordenados por Ricardo Luiz Silveira da Costa. ${ }^{58}$ Já no Rio de Janeiro, além dos já citados, há também o Laboratório Interdisciplinar de Teoria da História, Antiguidade e Medievo ${ }^{59}$ (formado em 2009 na Universidade Federal Rural do Rio de Janeiro - UFRRJ), o Núcleo de Estudos e Referências da Antiguidade e do Medievo $^{60}$ (criado em 2010 na Universidade Federal do Estado do Rio de Janeiro - UNIRIO), e o Translatio Studii-Núcleo Dimensões do Medievo (História, Língua e Filosofia) ${ }^{61}$, criado em 2007 e sediado na UFF. Enquanto no Paraná, ainda há o grupo Poder e Sociedade na Península Ibérica TardoAntiga e Medieval $^{62}$ (fundado em 2000 na Universidade Federal do Paraná - UFPR) e o Laboratório de Estudos Antigos e Medievais (formado em 2008 na Universidade Estadual de Maringá) ${ }^{63}$. No Rio Grande do Sul, vinculado ao GT de Estudos Medievais, há ainda o grupo Fontes para o ensino e pesquisa em História da Idade Média ${ }^{64}$ (criado em 2009 na Universidade Federal do Rio Grande do Sul - UFRGS). Para finalizar refiramos o laboratório Mnemosine,

${ }^{56} \mathrm{http}: / /$ dgp.cnpq.br/buscaoperacional/detalhegrupo.jsp?grupo=0392705GOX9JZB .

${ }^{57}$ http://dgp.cnpq.br/buscaoperacional/detalhegrupo.jsp?grupo=0392705W3DOY5F.

${ }^{58}$ Currículo Lattes: http://buscatextual.cnpq.br/buscatextual/visualizacv.jsp?id=B727344.

${ }^{59} \mathrm{http}: / /$ dgp.cnpq.br/buscaoperacional/detalhegrupo.jsp?grupo=021170518IU3BE.

${ }^{60} \mathrm{http}$ ://dgp.cnpq.br/buscaoperacional/detalhegrupo.jsp?grupo=1697705DOY5F9J.

${ }^{61} \mathrm{http}$ ://dgp.cnpq.br/buscaoperacional/detalhegrupo.jsp?grupo=00057058HPYR18; www. historia.uff.br/dimensoes/.

${ }^{62} \mathrm{http}: / /$ dgp.cnpq.br/buscaoperacional/detalhegrupo.jsp?grupo=010370549BZ5SC.

${ }^{63} \mathrm{http}: / /$ www.dhi.uem.br/index.php?option=com_content $\&$ view $=$ article \&id=1184\&Item $\mathrm{id}=225$.

${ }^{64} \mathrm{http}: / /$ dgp.cnpq.br/buscaoperacional/detalhegrupo.jsp?grupo=0192705HOY9JQ0. 
da UEMA - Universidade Estadual do Maranhão, fundado em $2006^{65}$ e os medievalistas do Grupo de Pesquisa "Imaginário e Cultura no Ocidente Medieval" da Universidade Federal do Amazonas, a primeira Universidade da região Norte do país a promover encontros sobre estudos medievais (em parceria com o Scriptorium) ${ }^{66}$.

\section{A investigação sobre História de Portugal: principais campos de interesse}

Procuraremos agora apresentar um panorama geral da investigação medievalística brasileira sobre História de Portugal medieval, de 1990 a 2010, centrando-nos nos trabalhos finais de pós-graduação (mestrados e doutoramentos), a partir dos seus resumos ou dos textos integrais, quando disponíveis na internet ${ }^{67}$. Um retrato completo deste campo teria que incluir necessariamente outro tipo de produção, como livros, artigos de revistas e contribuições para actas de congresso. Não sendo tal possível no âmbito deste artigo, e esperando que o venha a ser em breve, no quadro de futuras colaborações institucionais entre as universidades e centros de investigação portugueses e brasileiros, avançamos com a caracterização referida, que apesar das limitações, representa seguramente os principais campos de interesse. Impõe-se ainda explicitar que nos centrámos nas teses de História, pesem embora todas as dificuldades em delimitar esta área de estudo em relação à literatura, história de arte, história da música ${ }^{68}$. Por fim, as linhas que se seguem são um primeiro contributo, com fins antes de tudo informativos, e não pretendem de modo algum representar um estudo acabado de sociologia ou análise historiográfica/ /epistemológica da produção da temática circunscrita.

Algumas balizas quantitativas simples. Uma primeira constatação é a do volume da produção, e do aumento do seu ritmo. Para vinte anos - de 1990 a 2010 - o nosso levantamento identificou oitenta e oito teses; cinquenta e uma destas foram defendidas na primeira década do século XXI, em que anualmente se registou quase sempre crescimento, com dois picos em 2002 (nove teses)

${ }^{65} \mathrm{http}: / /$ dgp.cnpq.br/buscaoperacional/detalhegrupo.jsp?grupo=50587052AJDNU4 e site da revista "Outros tempos" - http://www.outrostempos.uema.br/.

${ }^{66} \mathrm{http}: / /$ dgp .cnpq.br/buscaoperacional/detalhegrupo.jsp?grupo=0082705MISZ9KU.

${ }^{67}$ Cfr. os Quadro I e II, em anexo. As referências a autores nas próximas páginas serão feitas sem notas, constando a informação completa destes dois Quadros.

${ }^{68}$ Como bem exemplifica $\mathrm{M}^{\mathrm{a}}$ Amparo Maleval, "Sobre os estudos medievais na área de Letras (no Brasil)", Atas da VI Semana de Estudos medievais, Atas da VI Semana de Estudos medievais, pp. 34-42 (disponível em http://www.pem.ifcs.ufrj.br/AtasVISem.pdf). 
e em 2005 (dez teses). Em termos de graduação alcançada, temos vinte e dois doutoramentos - um quarto, portanto. A relação adquire maior relevo ao ter-se em conta que os enquadramentos doutorais começam a tornar-se numerosos mais tarde, que a prova é muito mais morosa do que o mestrado, e que, por fim, implica já um maior comprometimento com decisões sobre carreiras profissionais. As dificuldades enfrentadas pelos medievalistas brasileiros, em relação a historiadores de outras épocas históricas, quanto de estabilização na estrutura universitária e a usufruto de bolsas de estudo, são referidas por toda a bibliografia.

Em termos de distribuição pelas universidades, a Universidade Federal Fluminense afirma-se como o principal centro de estudo, tanto em termos gerais (trinta e oito teses), como de especialização (dez doutoramentos, quase metade do total). Seguem-se-lhe a Universidade Federal do Rio de Janeiro (doze teses) e a Universidade de S. Paulo (dez teses), cabendo porém a esta o maior número de doutoramentos (seis contra um, eventualmente explicável pela co-existência de duas universidades com a mesma especialização no Rio de Janeiro, sendo uma delas de tradição anterior). Há depois três pólos de menor produção mas com crescimento recente: U. Federal do Paraná (sete teses, das quais três doutoramentos), Rio Grande do Sul e U. Estadual Paulista (ambas com seis teses de mestrado). As restantes universidades apresentam números inferiores de teses ou a produção diminuiu na última década.

Vejamos agora as grandes linhas temáticas. Em termos de investigação mais aprofundada, os vinte e dois doutoramentos revelam um claro pendor pela história das representações do poder ${ }^{69}$. A imagem do rei, a figura da rainha, a legitimação do poder dinástico através do espectáculo, os usos políticos do culto dos santos e da religião/estruturas eclesiásticas, no recorte temporal da Baixa Idade Média - eis os temas que mais comparecem, em geral associados à Universidade Federal Fluminense e à orientação da Professora Vânia Leite de Froes. Neste sentido, pode falar-se de uma escola de orientação bastante vincada e de uma prática continuada de análise de determinadas fontes, em especial as literárias (cronísticas, hagiográficas, prosa doutrinal, teatro vicentino e lírica trovadoresca, mas em menor grau). Estas fontes têm servido de base a teses realizadas noutras universidades, embora de forma menos concentrada -

\footnotetext{
${ }^{69}$ Cfr. uma análise matizada do total da temática, compreendendo os trabalhos extra "Portugal medieval" em Wanessa Asfora, Eduardo Henrik Aubert e Gabriel de Carvalho Godoy Castanho, "L’Histoire médiévale au Brésil", pp. 82 ss. Apresentamos os resumos disponíveis na Internet no Quadro III.
} 
refira-se o estudo da Virtuosa Benfeitoria por Gerson Silva, na USP (2001), a afectividade mística e emocional nas hagiografias medievais portuguesas por Teresa Candolo (UNICAMP, 2002), ou, por fim, o estudo de Edna Sala sobre a imagem feminina nas cantigas de escárnio e maldizer (UNESP, 2001).

São mais raras as abordagens de história social, a partir dos "actos da prática", mas encontram-se os estudos de Renata Nascimento sobre a prática do poder pela nobreza a partir dos documentos de cortes, de Gracilda Alves sobre a sociedade de um âmbito espacial específico (Pombal, Soure, Ega e Redinha), o mesmo estudado por Fabiano Fernandes sob o prisma do poder eclesiástico da Ordem de Cristo, a partir da documentação das comendas da região. As cartas de perdão serviram de base documental a dois doutoramentos recentes - em 2009, o de Denise Nascimento (sob a óptica específica do crime contra a integridade física e de honra, e tendo em conta as teorizações do poder régio medieval como uma instância negocial) e em 2010 o de Beatris dos Santos Gonçalves que, partindo daquele núcleo de fontes, alarga a paleta documental à legislação, aos capítulos de cortes, a fontes literárias, etc., para alcançar uma síntese sobre a relação entre o poder régio e os marginais (mais propriamente, as marginalidades), de novo sob o signo da "negociação/ composição" do poder(UFF). A história política e diplomática tem incidido sobre figuras régias (D. Dinis, Isabel de Aragão). Este tipo de teses tem sedes institucionais e direcções mais variadas, da UFRJ à USP e à Universidade Federal do Paraná, mas também pela UFF.

Também as dissertações de mestrado acusam uma forte quase total em torno das fontes literárias, o que se compreende tanto pela menor duração do trabalho de investigação, como pelas dificuldades de acesso aos documentos de arquivo em tempo útil (localização, paleografia, etc.). Têm sido exploradas sob os mais variados aspectos as crónicas régias e monásticas, os livros de linhagens, a produção palaciana (anedotas, poesia, apontamentos, etc.), a hagiografia, os textos teológicos e moralizantes, a lírica e a poesia satírica trovadoresca, os relatos de viagens. As perspectivas teóricas de interpretação situam-se, como referimos, muito na linha da actual História das representações, entre a abordagem francesa e a cultural history. Conceitos e temas da história antropológica - como a reciprocidade, a negociação, o dom, a circulação de bens simbólicos, ritos e cerimoniais - são chaves e áreas da abordagem dos temas muito diversas das praticadas em Portugal para estas mesmas fontes. Esta é porventura uma das áreas em que tudo ganharia em ser comum aos medievalistas portugueses e brasileiros o "mapeamento" do que está feito e a definição de rumos ainda possíveis de seguir. Há nas nossas bibliotecas muitas 
fontes afins por editar e explorar e o trabalho realizado ultimamente por equipas como a da BITAGAP, continua a revelar novos textos ${ }^{70}$. Ao mesmo tempo, os textos conhecidos têm tudo a ganhar com discussões teóricas sobre a forma de analisar o texto medieval, que escassamente chegaram a Portugal (e que no Brasil parecem algo alheias às propostas norte-americanas, por exemplo ${ }^{71}$. E em Portugal existe, a par de um know-how filológico, erudito e mais virado para a análise monográfica - seja por historiadores seja por estudiosos da literatura medieval - um cada vez menor número de pessoas a estudarem estes temas...

Encontra-se um segundo grupo de teses de mestrado que, embora centradas em fontes escritas, se alastram para além das literárias. Temos assim um número significativo de trabalhos feitos a partir de capítulos de cortes, de literatura jurídica e de legislação. Os livros de milagres, apesar de estarem na sua maioria publicados $^{72}$, têm atraído escassa atenção, apenas se destacando a tese de Beatriz Miranda sobre o santuário de Nossa Senhora da Oliveira (UFF, 1995). A cartografia, se bem que a par de fontes literárias mais utilizadas, proporcionou a Álvaro Mendes Ferreira uma interessante análise das "formas de apreensão do espaço" no Portugal da Expansão (UFF, 2010).

As poucas teses que trabalham fontes de arquivo merecem algum destaque - não simplesmente por isso - pois é possível fazer teses totalmente desinteressantes com a Torre do Tombo por perto! -, mas porque, fazendo-o, não deixam de colocar perspectivas novas e interessantes e de revelar um bom conhecimento das congéneres portuguesas. Referiria assim o trabalho sobre cartas de perdão de Beatris dos Santos Gonçalves (2005, UFRJ) e o estudo de Sooraya Medeiros sobre a realidade da condição jurídica feminina, que, a par do uso de fontes jurídicas impressas, trabalha um extenso corpus documental de variada tipologia, recolhido em diferentes fundos de arquivos de instituições eclesiásticas e régias (2007, USP).

Estes dois conjuntos de teses, movendo-se claramente mais na área da História social, não deixam de dedicar boa parte da investigação a campos afins das primeiras - representações, imagens, concepções. Há no entanto uma preocupação clara em alcançar o que é "representado", sempre em conexão

${ }^{70}$ Foi realizado, no dia 1 de Março de 2011, na FL-UL, um encontro sobre esta temática. O site da BITAGAP é http://sunsite.berkeley.edu/Philobiblon/phhmbp.html.

71 Jaume Aurell, "El nuevo medievalimo y la interpretación de los textos históricos", Hispania. Revista Española de Historia, vol. LXVI, nº 224 (Setembro-Dezembro 2006), pp. 809-832.

${ }^{72}$ Cfr. ponto da situação em Maria de Lurdes Rosa, p. 86, "Sociabilidades e espiritualidades na Idade Média: A historiografia portuguesa sobre os comportamentos religiosos dos leigos medievais", Lusitania Sacra, t. XXI (2009), pp. 75-124. 
com desenvolvimentos historiográficos actualizados, como sendo a forma de tratamento dos crimes ou a questão da graça e do perdão, na perspectiva sobretudo da medievalística francesa (Claude Gauvard e outros). Em termos de terrenos de colaboração, a exploração das fontes jurídicas e das cartas de concessão de graça especial, parece ser uma boa aposta, pois há diversos trabalhos recentemente defendidos e em elaboração, nas pós-graduações portuguesas, sobre estas fontes.

\section{Medievalismos pós-coloniais}

Sempre em registo breve e sobretudo de lançamento de propostas para correcção e diálogo - de que modo os medievalistas portugueses e brasileiros podem delinear inquéritos comuns?

Há um primeiro campo de trabalho, digamos, mais fácil. É clara a necessidade - e o interesse/vontade - em alargar o campo de fontes a utilizar. A medievalística portuguesa progrediu de forma exponencial quando, a partir dos anos ' 80 , o uso sistemático de fontes inéditas ou pouco exploradas até então, veio permitir cobrir muitas lacunas e corrigir visões demasiado generalistas. Esta necessidade obrigou a um esforço muito grande de ensino das disciplinas eruditas (em especial a paleografia), de edição de fontes e de descrição de fundos arquivísticos (aqui pode mesmo falar-se de um esforço titânico, dada a situação dos arquivos históricos, levado a cabo pelo Professor José Mattoso, pelas equipas que dirigiu, e pelas gerações de arquivistas formados nas novas correntes da função social do arquivo). Parece-nos poder afirmar que o direccionamento sistemático dos medievalistas brasileiros nestes âmbitos seria muito importante. Um terreno de trabalho comum seria portanto definir as maneiras mais simples, práticas e económicas, de realizar esta tarefa: estágios, cursos intensivos, programas de digitalização de fontes, identificação sistemática de edições de fontes a ceder, etc. A formação pós-graduada inicial poderia ser direccionada, em ambos os lados, para trabalhos neste âmbito, que familiarizem os estudantes com o universo heurístico disponível, a partir do conceito da sua produção na época "medieval", na linha do trabalho de Paolo Camarossano ${ }^{73}$, por exemplo. Esta é de resto uma prática cada vez mais obrigatória na formação de grau

${ }^{73}$ Paolo Camarossano, Italia medievale. Struttura e geografia delle fonti scritte, Roma, La Nuova Italia Scientifica, 1991; idem, "Strutture documentarie e strutture familiari in Italia dal X al XIII secolo", in Le médiéviste et la monographie familiale: sources, méthodes et problématiques, ed. Martin Aurell, pp. 81-86, Turnhout, Brepols, 2004. 
"mestrado" nas universidades portuguesa, dada a pouquíssima familiaridade com a investigação documental patenteada pelos formandos.

O "ida ao arquivo" ganharia ainda muito em ser - também para os que já lá vão...-, um verdadeiro "regresso ao arquivo", na linha não já da "recolha de informação" mas de compreensão dessa enorme construção que é o próprio arquivo e que é também o seu mais simples fundo. Na esteira do pós-colonialismo, globalização e temas afins, alguns historiadores e arquivistas têm vindo a interrogar cada vez mais a forma como o "Estado-nação" construiu os arquivos nacionais e/ou patrocinou edições de "fontes pátrias" ". Para os medievalistas - na verdade, para qualquer historiador de períodos anteriores ao século XIX - o conhecimento desta enorme "recomposição" do que chamamos os nossos materiais heurísticos, é absolutamente fundamental. Nos arquivos "nacionais" portugueses, está ausente boa parte da produção documental medieval e/ou está mal descrita e classificada outra. A reflexão dos historiadores sobre o que foi produzido - o que foi conservado - o que tem vindo (e como) a ser descrito - raramente ultrapassa considerações sobre os "documentos existentes". Tal compreende-se bem numa altura em que a "ida ao arquivo" era urgente, em que se trabalhava a partir de descrições arquivísticas rudimentares (ou se tinha, em geral, que as fazer, ao mesmo tempo que se fazia uma tese interpretativa), e em que pouco se estudava a questão da mediação arquivística do passado $^{75}$. Hoje em dia, tal não será mais possível.

Nada de consistente teria sido, ou poderá vir a ser feito, claro, se esta "viragem para o arquivo" tivesse sido, ou for, meramente positivista. No caso português a que aludimos, a existência concomitante de questionários interessantes e actualizados - sobre cidades, estrutura do funcionariato régio, nobreza, mosteiros, etc. - norteou as pesquisas. Estes questionários foram então, é forçoso reconhecê-lo, decalcados sobretudo da historiografia francesa, mas o contacto com as fontes, indiciando realidades diversas, permitiu, nos melhores trabalhos, um redesenhar de temas e problemas. Todo este processo

${ }^{74}$ B. DELMAS, Ch. NOUGARET (eds.), Archives et nations dans l'Europe du XIXe siècle, Paris, École Nationale des Chartes, 2004; Archivi e storia nell'Europa del XIX secolo, 2 vols, Roma, Ministerio per i Beni Culturali, 2006; e Patrick Geary, O mito das nações. A invenção das origens medievais da Europa, Lisboa, Gradiva, 2008.

${ }^{75}$ Pensamos em propostas como a de Fernanda Ribeiro, $\mathrm{O}$ acesso à informação nos arquivos, 2 vols., Lisboa, FCG/ FCT, 2003; Joseph Morsel, «Du texte aux archives: le problème de la source», "Le Moyen Âge vu d'ailleurs", Bulletin du Centre d'Études Médiévales d'Auxerre, h.s $\mathrm{n}^{\circ} 2$ (2008), (http://cem.revues.org/index4132.html); e Terry Cook, "The Archive(s) is a foreign country: historians, archivists and the changing archival landscape", in The Canadian Historical Review, 90, n 3 (Setembro 2009), pp. 497-534. 
está ainda em andamento, tanto em Portugal como no Brasil, e num local e noutro existem, parece-nos justo afirmar, aporias teóricas a limar. Entre outras, referiríamos a excessiva dependência das propostas historiográficas francesas, e algum alheamento - porventura mais notório em Portugal do que no Brasil das sucessivas releituras e "viragens" a que temos vindo a assistir nos últimos 20 anos. A proposta aqui seria a de uma reflexão conjunta sobre os modelos teóricos que diversos medievalismos têm vindo a definir, alguns dos quais parecem especialmente operativos. Em primeiro lugar, enriquecer a ideia da "longa duração" - fundamental para o trabalho sobre o tema - com as propostas em torno de conceitos como "alteridade"76, "sociedades pré-modernas" "77, "sociedades não-modernas" ${ }^{\text {" }}$, ou as discussões sobre a periodização da História ocidental e a forma como a cronologia é uma questão política e de poder ${ }^{79}$. A teorização dos "usos da Idade Média", problema concomitante ao anterior, tem também conhecido enormes desenvolvimentos nas correntes agrupadas sob a designação de "medievalism", originárias dos EUA mas com crescente implantação noutros locais ${ }^{80}$.

${ }^{76}$ Paul Freedman, Gabrielle Spiegel, "Medievalisms old and new"; Gabrielle M. Spiegel, «L'itinéraire postmoderniste du médiévisme américain: l'altérité médiévale redécouverte», Les Cahiers du Centre de Recherches Historiques, 22 (1999)(http://ccrh.revues.org/index2462. html); Joseph Morsel, Ch. Ducourtieux, L'Histoire (du Moyen Âge) est un sport de combat... Réflexions sur les finalités de l'Histoire du Moyen Âge destinées à une société dans laquelle même les étudiants d'Histoire s'interrogent (lamop.univ-paris1.fr/W3/JosephMorsel/index.htm).

${ }^{77}$ Entre muitas outras abordagens sobre este tema em relação com a I. Média, cfr. o volume 36-1 do Journal of Medieval and Early modern studies (2006), dedicado ao tema "Theory and the study of premodernity" e uma contra-discussão inovadora sobre as continuidades em Andrew Cole e D. Vance Smith (eds.), The legitimacy of the Middle Ages. On the unwritten history of theory, Durham e Londres, Duke UP, 2010.

${ }^{78}$ José Rabasa, "Decolonizing medieval Mexico", pp. 31 ss, in Nadia Altschul, K. Davis (eds.), Medievalisms in the postcolonial world, Baltimore, Johns Hopkins UP, 2009, pp. 27-50.

${ }^{79}$ Cfr. o volume 37-3 do Journal of Medieval and Early modern studies (2007), dedicado ao tema "Rethinking periodization"; e, numa análise de fundo, Kathleen Davis, Periodization and sovereignty. How ideas offeudalism and secularization govern the politics of time, Philadelphia, U. Pennsylvania P., 2008, que discute longamente o trabalho de R. Koseleck, fonte de boa parte da teorizações da "longa I. Média".

${ }^{80}$ Esta abordagem tem gerado uma enorme bibliografia. Remetemos aqui para os três principais sites de organizações universitárias que nela trabalham: http://www.medievalism. net/, e http://studiesinmedievalism.blogspot.com/, do colectivo ligado à continuação da obra daquele que pode ser considerado um dos fundadores destes estudos, Leslie Workman; na Europa, o http://www.uni-due.de/perspicuitas/, da Universidade de Dresden, com uma parte sobre o tema, animada por R. Utz, ligado ao grupo anterior; e em França, oriundos de uma tradição diferente e trabalhando mais sobre a literatura, mas já com colaboração com os primeiros, a Associação «Modernités médiévales» (http://www.modernitesmedievales.org/). 
Cremos que quer um quer outro campo teórico, e os muitos estudos que se têm neles realizados, proporcionariam uma excelente plataforma de discussão para o tema da "continuidade/ actualização" da Idade Média no Brasil. Este tema interessa sobremaneira a ambos os grupos de historiadores, e deveria de resto ser feito em diálogo com os Modernistas (em Portugal, pelo menos, há um deficit de diálogo entre medievalistas e modernistas, com a agravante de junto a estes existirem ainda os "Expansionistas", sendo que os dois grupos, com demasiada frequência, dividem o estudo do Portugal de inícios do séc. XV em diante, em território continental e territórios ultramarinos). Não é de facto só uma questão de identidade brasileira, mas também um excelente "laboratório" em que os medievalistas de ambos os países dispõem de muito mais e mais variadas fontes. Dois textos especialmente interessantes a este respeito são a tentativa de compreensão global da relação feita por Hilário Franco Jr. em "Racines médiévales du Brésil" ", e a proposta de interpretação de um aspecto concreto, as "lutas entre Cristãos e mouros" como "ritualização da conquista", da autoria de José Rivair de Macedo ${ }^{82}$. Mas o tema tem merecido atenção de muitos outros autores e reuniões científicas, brasileiras e luso-brasileiras ${ }^{83}$. A reflexão, intermitentemente presente na cultura latino-americana e brasileira, recebeu, no campo mais restrito dos historiadores medievalistas, um poderoso impulso da relativamente recente mas influentíssima obra de Jérôme Baschet, editada no Brasil em 2006, que propõe uma releitura do "final" da Idade Média, e das rupturas/continuidades para o "Novo Mundo", terminando por

${ }^{81}$ Hilário Franco Júnior, "Racines médiévales du Brésil", "Le Moyen Âge vu d'ailleurs", Bulletin du Centre d'Études Médiévales d'Auxerre, h.s no 2 (2008) (http://cem.revues.org/ index4082.html).

${ }^{82}$ José Rivair de Macedo "Mouros e cristãos: a ritualização da conquista no velho e no Novo Mundo", Bulletin du Centre d'Études Médiévales d'Auxerre, h.s n 2 (2008) (http://cem.revues. org/index8632.html).

${ }^{83}$ Entre outros, e tocando os tema das continuidades, por vezes, via "medievalismo", Ma Amparo Maleval (org.), Atualizações da Idade Média, Rio de Janeiro, Ágora da Ilha, 2000; Medievalismo: leituras contemporâneas, 2005, Londrina. Anais do VI Encontro Internacional de Estudos Medievais, Londrina, Universidade Estadual de Londrina, 2005; Roberto Pontes e Elizabeth Dias Martins (org.), Anais do VII Encontro Internacional de Estudos Medievais - Idade Média: permanências, atualização, residualidade, Fortaleza/Rio de Janeiro, UFC/ABREM, 2009. O tema do encontro luso-brasileiro de História medieval de 2010 foi precisamente " A Idade Média portuguesa e o Brasil: reminiscências, transformações, ressignificações" (cfr. supra, nt. 25). Uma síntese das problemáticas pode ver-se em Gulherme Queiroz de Sousa, "O prolongamento do mundo medieval, na conquista e colonização do novo Mundo: uma abordagem teórico-metodológica historicizada”, XIV Encontro regional da ANPUH-Rio (Julho 2009, disponível em http://www.encontro2010.rj.anpuh.org/resources/anais/8/1275361732_ARQUIVO_ TextoGuilhermeQueirozdeSouza-Anpuh-RJ.pdf). 
apelar à reflexão sobre o tema e à construção de conceitos e investigações no seu âmbito ${ }^{84}$. Este parece ser um dos mais fecundos campos de realização de inquéritos comuns.

A persistência de modelos e estruturas de sociedades pré-modernas (chamemos-lhe assim por comodidade) e a perspectivação da "Idade Média" como tal, apela a que se formulem questões sobre a adequabilidade de instrumentos e posturas de análise historiográficas potencialmente anacronizantes e presentistas. A antropologia histórica tem sido uma das mais fecundas vias de estudo da Idade Média, pesem embora todas as críticas que lhe possam ser feitas - e que, valha a verdade, têm em geral incidido mais na necessidade de aperfeiçoar e adequar metodologias do que alinhado na rejeição total dos princípios teóricos ${ }^{85}$. A historiografia medievalística brasileira está bem mais familiarizada do que a portuguesa com as propostas de uma das principais correntes desta abordagem, a fundado por Jq. Le Goff (continuando Marc Bloch) e prosseguida por Jean-Claude Schmitt; ambas poderiam beneficiar de um maior contacto com abordagens afins como a de medievalistas americanos como L. Little, B. Rosenwein, P. Geary, S. White, entre outros, e com as mais recentes aportações dos "subaltern studies" e outras correntes dos estudos pós-coloniais, que Bruce Holsinger demonstrou terem-se inspirado também nas reformulações teóricas dos medievalistas franceses que, nos anos '60 e "70, procuravam alcançar as "vozes dos sem voz" e estudar temas como a cultura dos não-literatos numa sociedade medieval dominada pela instituição "imperial" Igreja"86. O trabalho a partir destas leituras poderá ser uma maneira

${ }^{84}$ Jérôme Baschet, La civilisation féodale. De l'an Mil à la colonisation de l'Amérique, pp. 339-415, $3^{\text {a }}$ ed rev e actual., Paris, Flammarion, 2006 pp. 339-415.

${ }^{85}$ Para uma visão actual, consultem-se as comunicações apresentadas ao Colóquio evocativo dos 30 anos do GAHOM, E. Brilli, P.-O. Dittmar, B. Dufal (orgs.), Faire l'anthropologie historique du Moyen Âge, L'Atelier du Centre de Recherches Historique, 7, 2010, (http://acrh.revues.org/ index 1911.html).Para as críticas, além desta obra, cfr. por ex. Philippe BUC, The dangers of ritual. Between Early Medieval Texts and Social Scientific Theory, Princeton, Princeton UP, 2001 e Barbara H. Rosenwein, "Francia and Polynesia: rethinking anthropological approaches" in Gadi Algazi, Valentin Groebner, Bernhard Jussen (eds.), Negotiating the gift: pre-modern figurations of exchange, pp. 361-380, Göttingen, Vandenhoeck \& Ruprecht, 2003 (e outros no mesmo volume).

${ }^{86}$ Sobre os usos da teorização pós-colonial pelos medievalistas (e vice-versa), cfr. Bruce Holsinger, "Medieval studies, postcolonial studies, and the genealogies of critique", Speculum, 77 (4) (Outubro 2002), pp. 1195-1227. Entre os primeiros estudos que aplicaram as propostas "pós-coloniais" à I. Média, é consensual K. Biddick, "Decolonizing the English past; readings in medieval Archaeology and History", Journal of British Studies, 32 (Janeiro 1993), pp. 1-23; um ponto de chegada da primeira fase pode ver-se em Jeffrey J. Cohen (ed.), The postcolonial Middle Ages, N. Iorque, Palgrave, 2000 ou no volume temático do mesmo ano do JMEMS 
de olhar "de outro modo" a Idade Média europeia, desconstruindo e não reproduzindo visões demasiado identitárias. No primeiro e último rescaldo do Programa "Le Moyen âge vue d'ailleurs", Joseph Morsel e Eliana Magnani interrogam-se, respectivamente, sobre a possibilidade dos medievalistas sul-americanos construírem uma Idade Média “autrement vue" ou "vue d'ailleurs", precisamente por excesso de filiação/ legitimação através do passado colonial e eventual ausência de reflexões de tipo pós-colonial ${ }^{87}$.

Não se advoga porém que isto seja especialmente possível a partir de - e muito menos "próprio a" - universidades e investigadores localizados em "zonas mais arcaicas" do mundo "moderno" (o Brasil em relação à América não colonizada por portugueses e/ou ibéricos, ou em relação à Europa, Portugal em relação à "Europa além Pirenéus"). A atribuição da condição periférica é normalmente feita a partir dos "centros" que visam implementar ou reforçar a sua supremacia. A definição de rumos a seguir ganharia assim, quanto a nós, com um esforço de reflexão sobre a constituição dos campos disciplinares medievalistas português e brasileiro. Aqui os conceitos dos estudos pós-coloniais podem com todo o sentido aplicar-se à estrutura de produção do conhecimento e não à sociedade pré-moderna que se estuda ${ }^{88}$. De que modo uma afirmação académica do medievalismo português e ibérico feita na periferia e dependência de estruturas académicas, cientificas e estatais (pois assim se devem entender as universidades oitocentistas) mais fortes, ditou os nossos rumos, problematizações e sínteses, indo para além do conceito de influência científica? Tem sentido falar de uma "especificidade da Idade Média peninsular"? Específica em relação a quê? Ao modelo de "Idade Média" tal como foi construído pelos medievalistas franceses e alemães do século XIX? Seguramente que este modelo foi interrogado de forma total pelos seus sucessores, alguns dos quais deram dados contributos

(John Dagenais, Margaret R. Greer (introd.), "Decolonizing the Middle Ages: introduction", Journal of Medieval and Early Modern Studies, vol. 30, n⿳ 3 (2000, Outono), pp. 431-448. Novas experiências de aplicação dos conceitos podem ver-se em Postcolonial approaches to the European Middle Ages. Translating cultures, ed. Ananya J. Kabir, Deanne Williams, Cambridge, C.U.P., 2005 e em Medievalisms in the postcolonial world.

${ }^{87}$ Eliana Magnani,'Entre politique et disciplinaire: les études médiévales en Europe et en Amérique latine", p. 10; Joseph Morsel, "Le Moyen Âge vu d'ailleurs", p. 3, Bulletin du Centre d'Études médiévales d'Auxerre, 7 (2003) (http://cem.revues.org/index3172.html).

${ }^{88}$ Como já foi praticado no número 30 (3) do Journal of Medieval and Early Modern Studies, acima referido, nos artigos de Espósito, Hanlon e López Baralt; as relações de poder entre as academias europeias e um medievalista sul-americano são estudadas de forma interessantíssima em Nadia Altschul, "Andrés Bello and the Poem of the Cid. Latin America, occidentalism, and the foundations of Spain's 'National philology"', in Medievalims in the postcolonial world, pp. 219-236. 
decisivos para a construção de uma Idade Média livre de anacronismos e de mecanismos identitários. No entanto, no discurso histórico de base (e não só), a história dos territórios peninsulares no período a que se convencionou chamar Idade Média, continua a ser feita à luz daquele modelo. Eé assim possível falar de "atrasos", de "bloqueios", de "arcaísmos", e prossegui-los para a sociedade que os homens do Portugal de finais do século XV em diante, transplantaram para o Brasil. Haverá características sociológicas das áreas civilizacionais que as tornam mais ou menos permeáveis ao novo, mais ou menos resistentes à mudança, mais ou menos predispostas a transpor para outras áreas as suas estruturas? Esteve Portugal nesta condição quando partiu para os Mares, no que seria uma surpreendente forma de "inovar tradicionalmente"? O Brasil "nasceu" desta condição? O debate é científica e culturalmente vastíssimo, pelo que seria vão querer resumi-lo aqui. Para os medievalistas, como cientistas que são, a tarefa é de determinar e problematizar rigorosamente estes parâmetros.

O espaço disponível impõe limites. Poderíamos referir vários outros temas, mas ficamos por um que nos parece seguramente o mais caro a todos os professores e alunos que gostaríamos de ver envolvidos neste "reforço do diálogo". Porquê estudar a Idade Média? A pergunta, no tropical, variadíssimo e supersónico Brasil de hoje, parece realmente merecer uma rápida resposta negativa - como acusam tantos textos aqui evocados e a mais superficial conversa com medievalistas brasileiros. Mas não está porém nada ausente no "país com as mais antigas fronteiras da Europa", com tantos e ilustres pergaminhos medievais. Também em Portugal os estudos medievais têm sido, na última década, afectados por problemas vários, contando-se entre os mais imediatos uma diminuição séria dos financiamentos em projectos de investigação (sem que para tal se vislumbre um motivo claro ${ }^{89}$ ), bem como a escassez de alunos e investigadores novos. O que podemos fazer, num esforço portanto naturalmente comum, passa também por uma auto-crítica e correcções de rumo, e é nestes aspectos que aqui insistiríamos - sem minimizar factores globais, alheios aos medievalistas, mas optando por gerir o que nos é mais próximo. E recusando legitimações nacionalistas.

Porquê estudar, porquê ensinar a Idade Média, passa pela questão do "como fazê-lo" e pela maneira como conseguimos transmitir o enorme interesse de

${ }^{89}$ RODRIGUES, Ana Maria - "Projectos de investigação em História Medieval financiados pela FCT nos últimos 10 anos". Medievalista online, 9, (Dezembro de 2010). http://www2 fcsh. unl.pt/iem/medievalista/MEDIEVALISTA9/rodrigues9002. 
poder fazê-lo de forma complexa ${ }^{90}$. Numa linguagem pedagógica actualizada, poderíamos falar do desenvolvimento de competências a partir do nosso saber específico.

Um dos maiores ganhos de toda a reflexão medievalística dos últimos vinte anos, é a interrogação do local de onde se fala, das genealogias disciplinares, dos problemas e vícios de contexto. Neste aspecto, qualquer medievalista lido nesta reflexão, treina-se profundamente na interrogação da sua prática historiográfica. Torna-se um hábito mental a recusa das leituras identitárias do passado, - modernizantes ou anacronizantes conforme a identidade do leitor. Por outro lado, o trabalho sobre um mundo que nos chega de forma extremamente fragmentária, aguça a capacidade de pesquisa, a prática de interrogar os silêncios, de estudar a pertinência da amostra. A consciência dos efeitos da passagem do tempo sobre os vestígios do passado, alerta-nos para a necessidade de estudar a forma da sua transmissão e, num âmbito patrimonial, de os preservar e de cuidar do presente. A paciente reconstituição de um mundo diverso do nosso a que somos obrigados, predispõe-nos para a compreensão e aceitação de outras formas de organização do mundo. Um passado que temos que reconstruir e interpretar ajuda-nos a usar menos as analogias simples, a recusar para os historiadores uma postura de áugures, a teorizar correctamente complexamente - a evolução e a permanência. Enfim, a recusa da "modernização do passado" como condição para que ele se torne compreensível e, ao invés, a insistência no esforço de despaísamento necessário a qualquer compreensão da diferença, faz-nos mais tolerantes, científica e pessoalmente.

\footnotetext{
${ }^{90}$ Gabrielle Spiegel, Spiegel, "'Getting Medieval': History and the Torture Memos", Perspectives on History, 46, 6 (Setembro 2008) (http://www.historians.org/perspectives/ issues/2008/0809/0809pre1.cfm) e a discussão da posição da influente historiadora em Ellen Joy, "Signaling to Each Other from Inscrutable Depths: A Response to Gabrielle's Spiegel's "'Getting Medieval': History and the Torture Memos" no blogue "In the Middle" (http:// www.inthemedievalmiddle.com/2009/03/signaling-to-each-other-from.html); Alain Guerreau, "Situation de l'Histoire médievale", Medievalista online, 5 (2008); (http://www2.fcsh.unl.pt/ iem/medievalista/MEDIEVALISTA5/PDF5/01-Alain-Guerreau.pdf); Judite Freitas, “A memória social par ao futuro: História, alteridade e cidadania", Medievalista online, 5 (2008) (http:// www2.fcsh.unl.pt/iem/medievalista/MEDIEVALISTA5/medievalista-freitas.htm).
} 


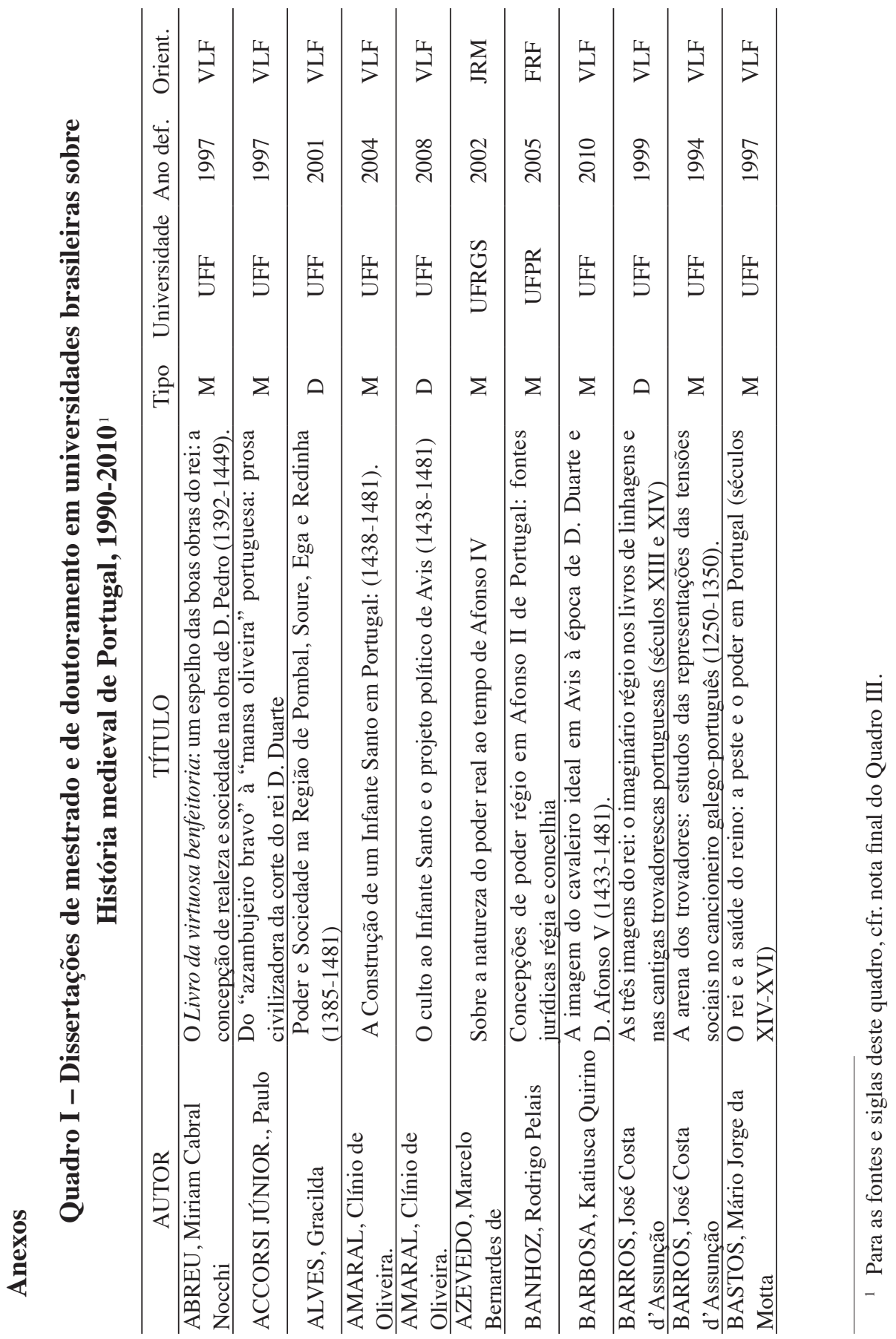




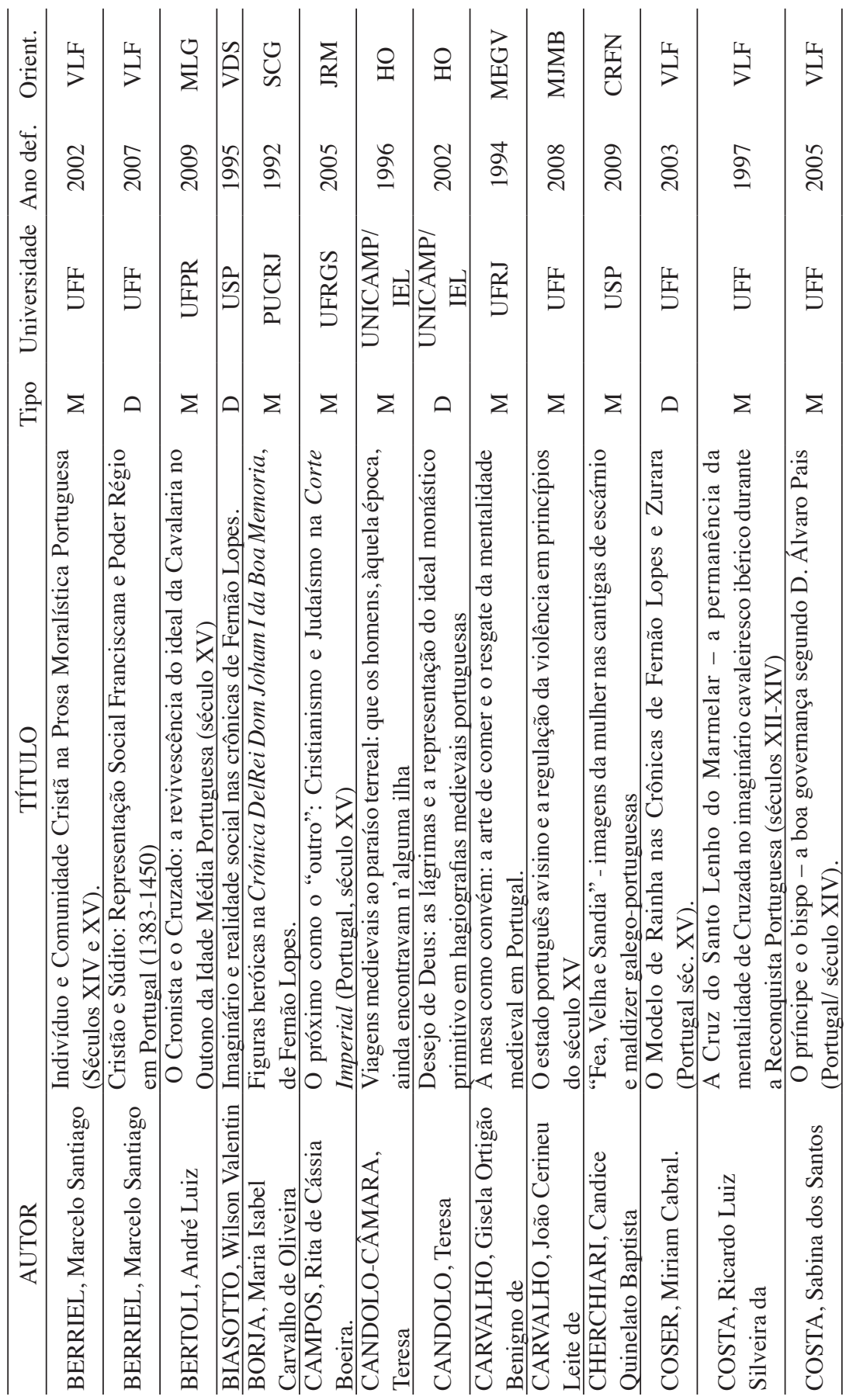




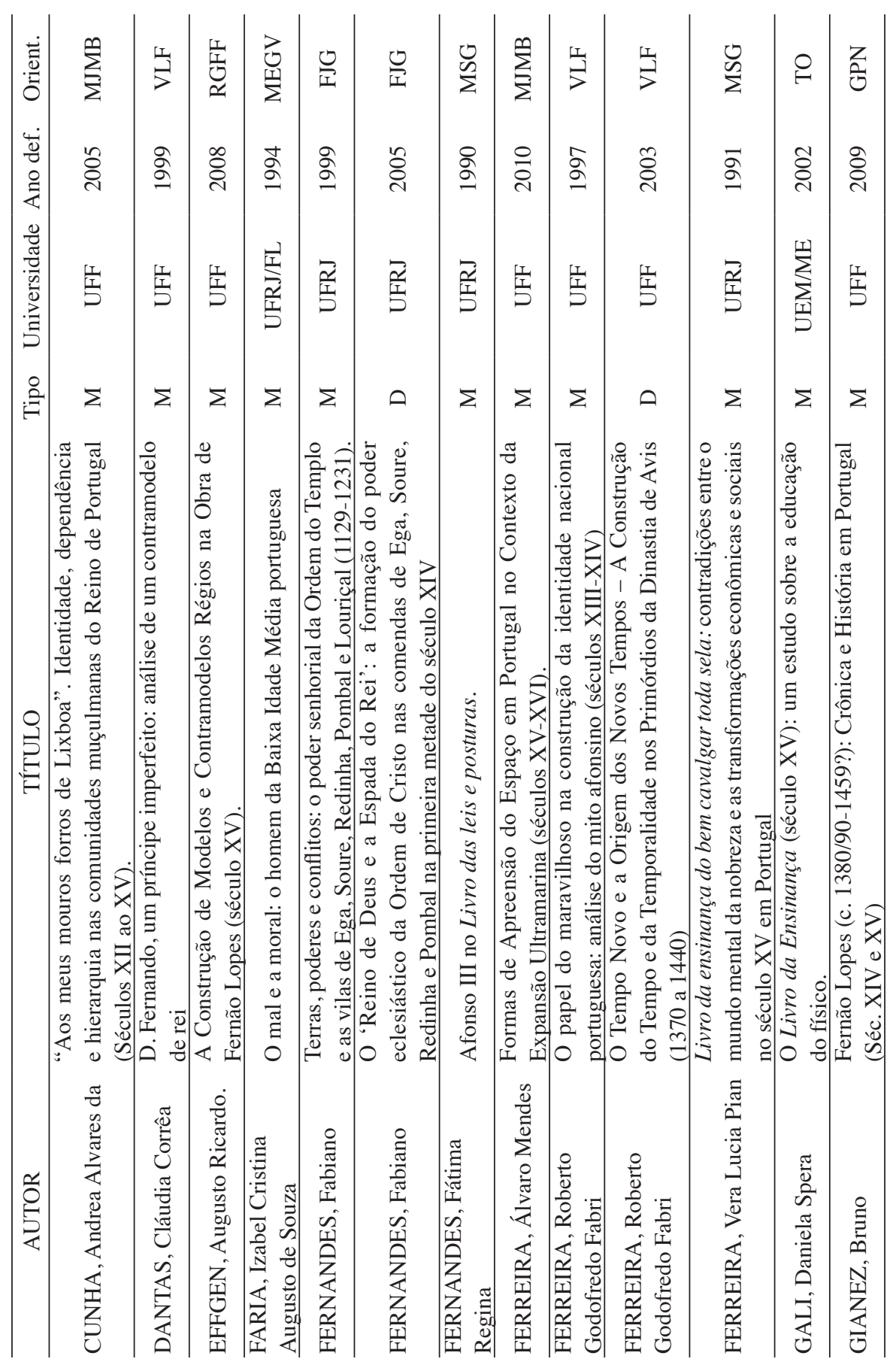


Maria de Lurdes Rosa e André Bertoli

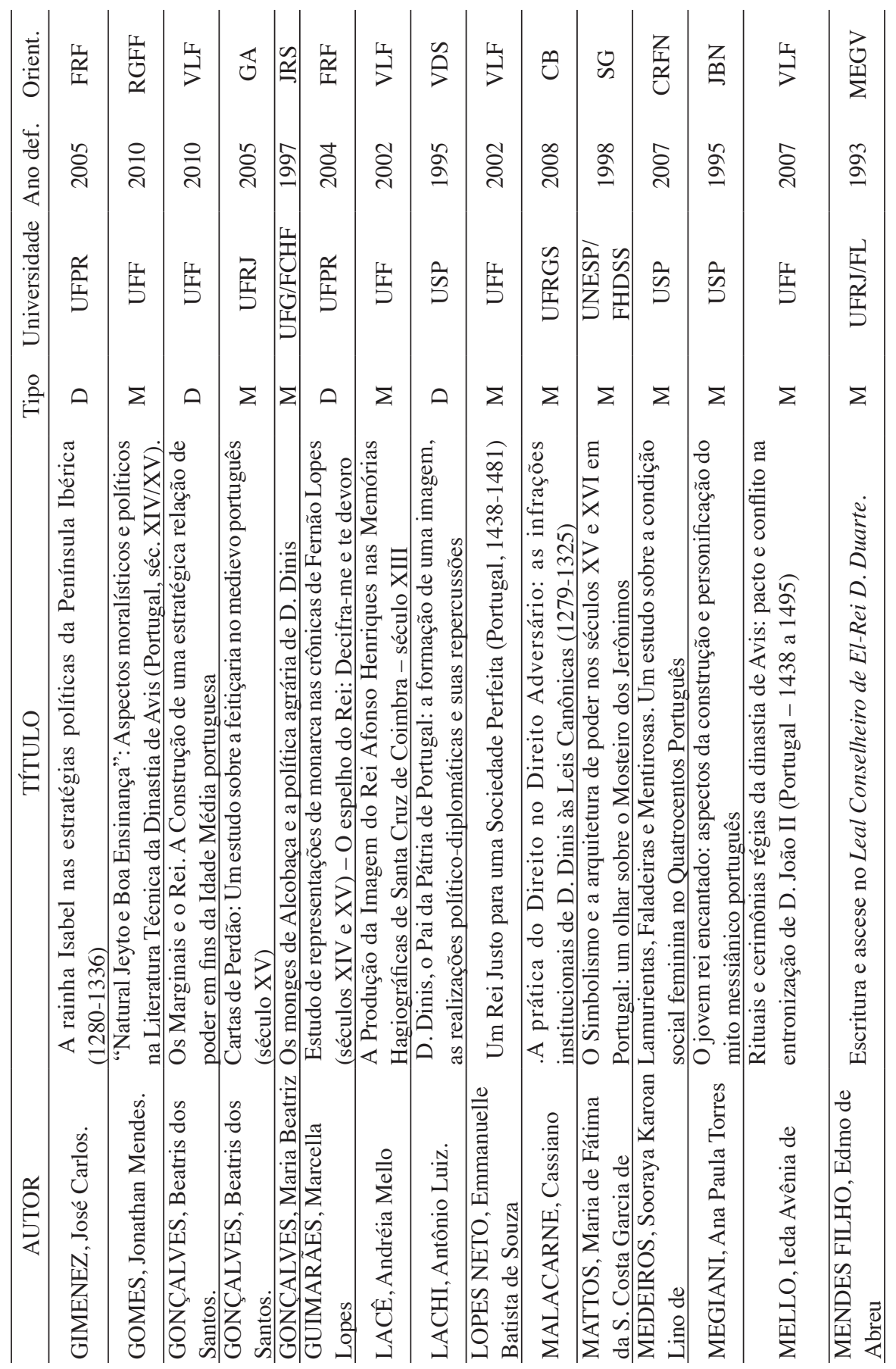




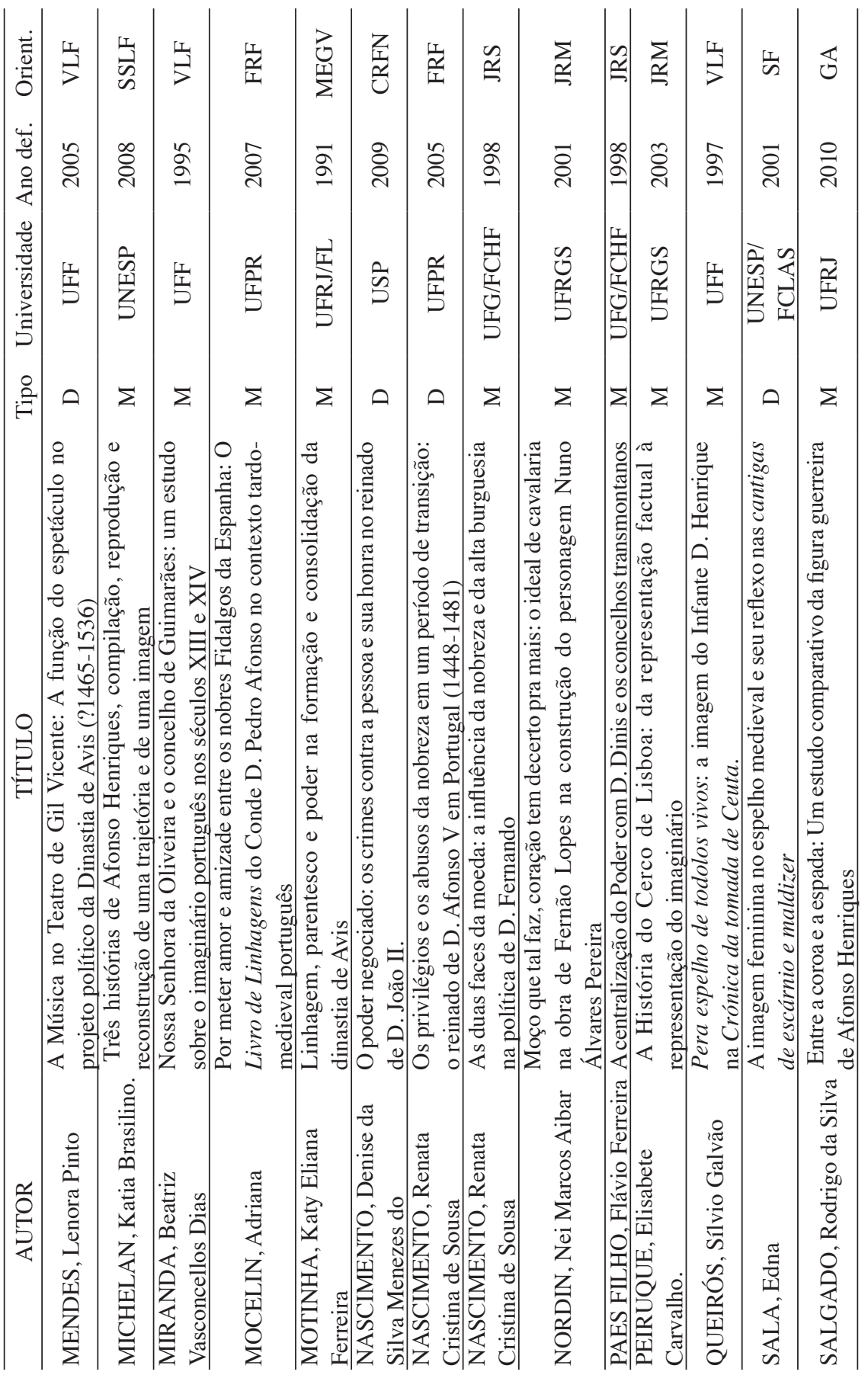




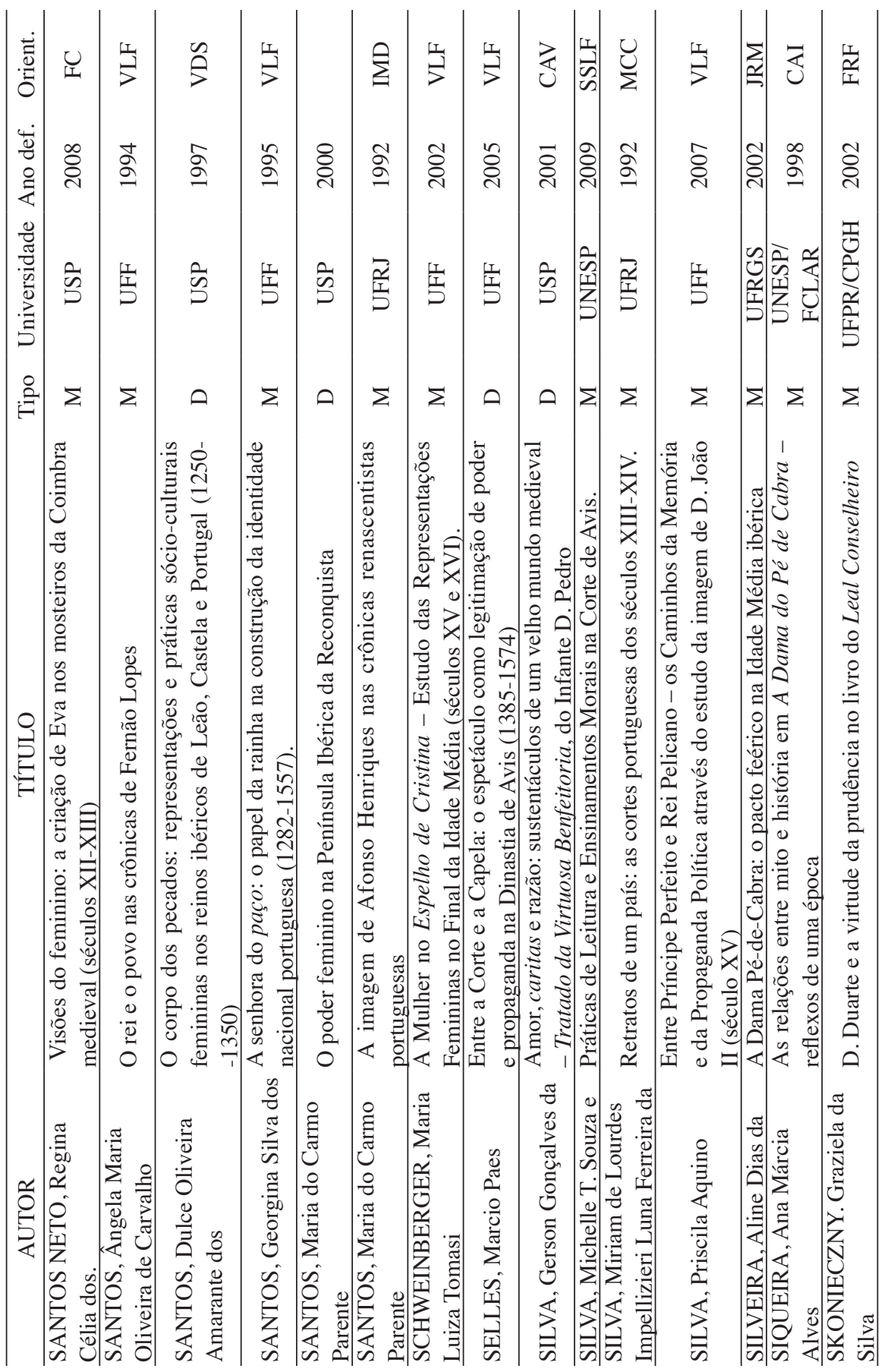




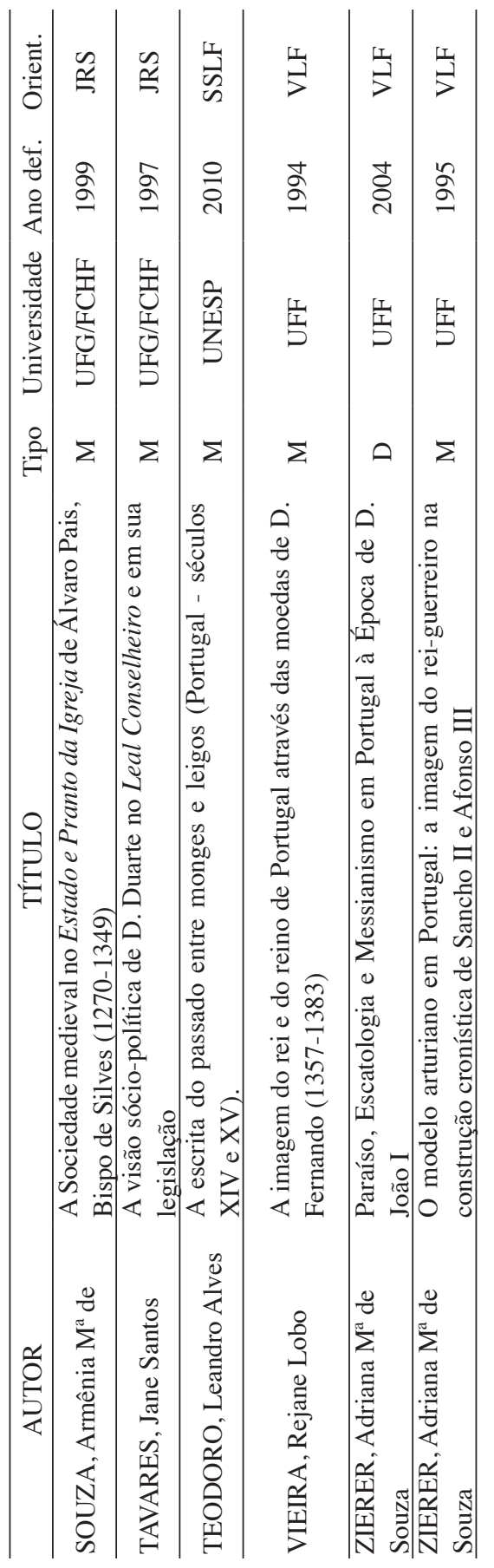


Maria de Lurdes Rosa e André Bertoli

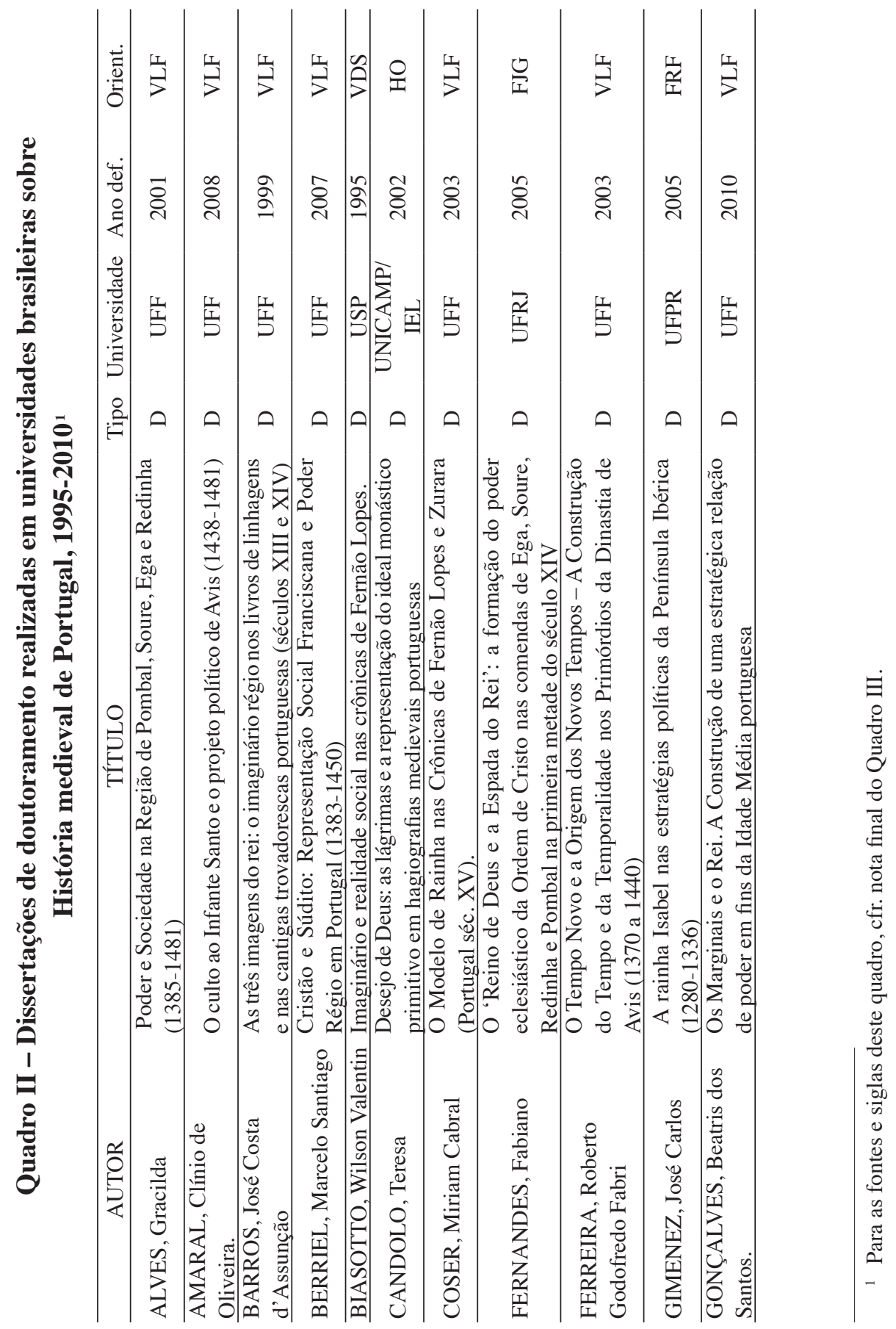




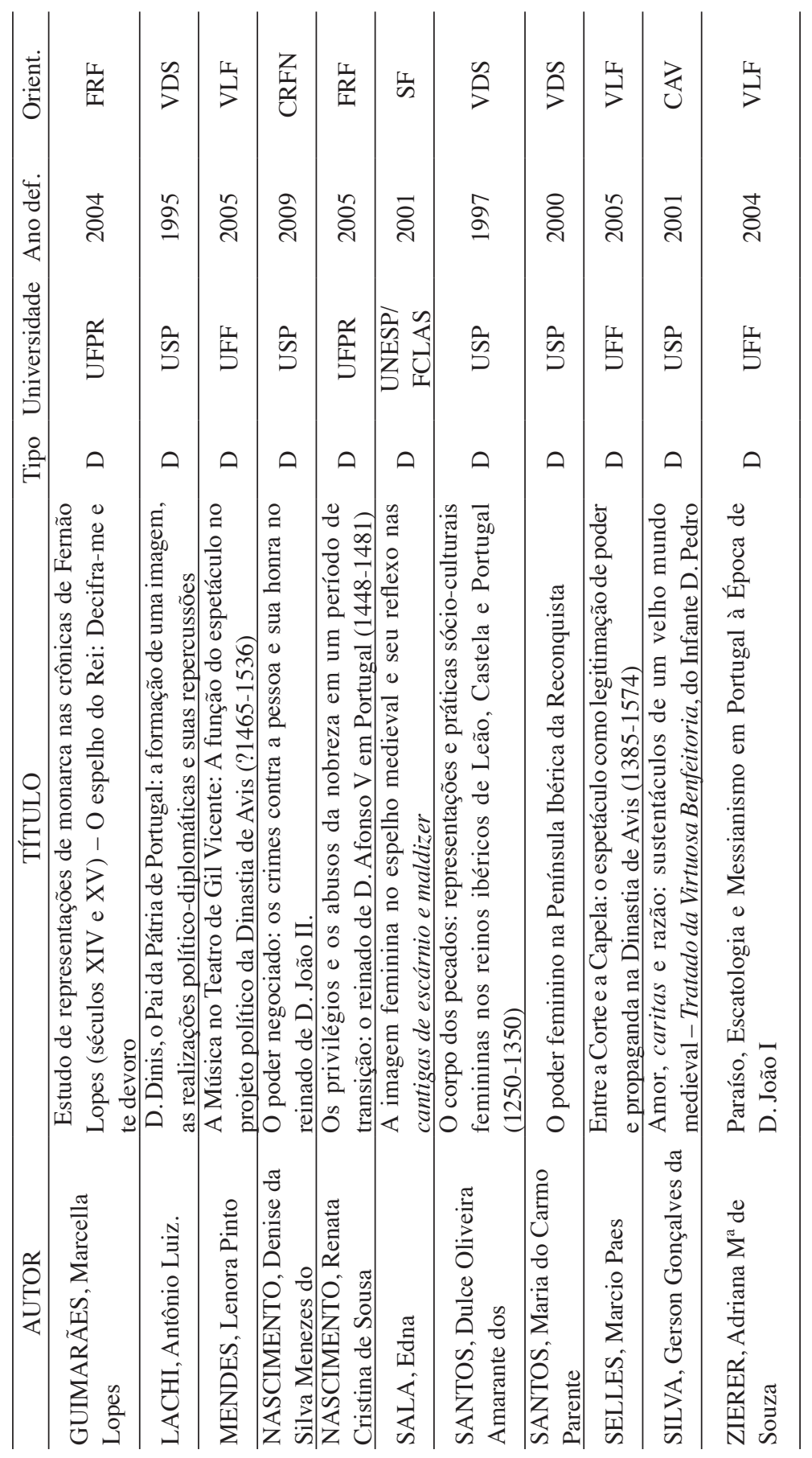




\section{Quadro III - Resumos das teses de doutoramento sobre Portugal medieval realizadas em universidades brasileiras}

Alves, Gracilda. Poder e Sociedade na Região de Pombal, Soure, Ega e Redinha (1385-1481). Esta tese foi organizada em torno de três eixos: a caracterização física e espacial da região; o estudo da população e dos mecanismos de povoamento; e finalmente, o mapeamento do jogo de poderes, que se concretiza nos senhorios (leigos e eclesiásticos), nos conselhos e pelo rei e seus agentes. Este estudo foi realizado no Setor Temático de História Medieval, Baixa Idade Média (séculos XIV e XV). ${ }^{1}$

Amaral, Clínio de Oliveira. O culto ao Infante Santo e o projeto político de Avis (1438-1481). Neste estudo desenvolvido no Setor de História Medieval, Baixa Idade Média, ao deslindar as especificidades do culto ao Infante D. Fernando, o autor buscou demonstrar como a representação da santidade daquele foi construída com base em dois momentos: inicialmente, as "autoridades", cronistas e hagiógrafos associaram a vida de D. Fernando à trajetória de um mártir, para, depois, vincularem a imagem do seu martírio ao projeto expansionista do reinado de $\mathrm{D}$. Afonso $\mathrm{V}^{2}$

BARros, José Costa d'Assunção. As três imagens do rei: o imaginário régio nos livros de linhagens e nas cantigas trovadorescas portuguesas (séculos XIII $e X I V)$. O autor destaca o processo de centralização do poder e a imagem do rei através do imaginário régio nos séculos XIII e XIV, tendo como fontes os Livros de linhagens e os cancioneiros produzidos durante os reinados de D. Afonso III e D. Dinis. Assim, a produção cultural da nobreza e do paço é encarada como forma de enfrentamento entre realeza, nobreza e outros grupos. ${ }^{3}$

Berriel, Marcelo Santiago. Cristão e Súdito: Representação Social Franciscana e Poder Régio em Portugal (1383-1450). O autor analisa a estrutura da representação social de Cristo no discurso franciscano, associando-a a noção de Súdito, que, no campo simbólico, definiu um equilíbrio entre os poderes temporal e espiritual e serviu ao uso ideológico por parte da dinastia de Avis.

\footnotetext{
1 Referência e resumo disponível em: http://www.historia.uff.br/stricto/tesesdata.php.

2 Texto completo disponível: http://www.historia.uff.br/stricto/teses/Tese-2008_AMARAL_Clinio_ de_Oliveira-S.

3 José Rivair de Macedo (org.). Os Estudos Medievais no Brasil, p. 33; http://www.historia.uff.br/ stricto/tesesdata.php.
} 
Dentre as fontes estudadas, destacam-se as obras Horologium Fidei, A História Seráfica da Ordem dos Frades Menores de S. Francisco, as Crónicas da Ordem dos Frades Menores, a Crónica de D. João I, a Crónica da Tomada de Ceuta e o Livro da Vertuosa Benfeytoria. ${ }^{4}$

Biasotto, Wilson Valentin. Imaginário e realidade social nas crônicas de Fernão Lopes. Em seu trabalho Biasotto analisou a concepção histórica de Fernão Lopes, na qual buscou compreender a influência da religião na construção da História e no imaginário do "homem medieval português". 5

CAndolo, Teresa. Desejo de Deus: as lágrimas e a representação do ideal monástico primitivo em hagiografias medievais portuguesas. Análise das lágrimas como elemento significativo nas hagiografias medievais portuguesas. São estudados o corpus de hagiografias - a Collecção Mystica de Frei Hylario de Lourinhaã, do códice Alc. $462 .{ }^{6}$

Coser, Miriam Cabral. O Modelo de Rainha nas Crônicas de Fernão Lopes e Zurara (Portugal séc. XV). Análise do modelo de rainha elaborado pelos cronistas oficiais, Fernão Lopes (1380-1460) e Gomes Eanes de Zurara (1420-1474). A autora procurou demonstrar que o modelo - marcado por uma oposição entre as mulheres identificadas com Portugal e aquelas identificadas com Castela - constitui em uma releitura do modelo feminino da matriz cristã medieval, que opunha Maria a Eva e insere-se num discurso mais amplo, relacionado com a formação da identidade nacional portuguesa. Pesquisa realizada no Setor Temático de História Medieval, Baixa Idade Média. ${ }^{7}$

Fernandes, Fabiano. $O$ 'Reino de Deus e a Espada do Rei': a formação do poder eclesiástico da Ordem de Cristo nas comendas de Ega, Soure, Redinha e Pombal na primeira metade do século XIV. Fabiano Fernandes defendeu sua Tese de Doutorado na linha de pesquisa Sociedade e Cultura, com o objetivo de discutir o processo de formação do poder eclesiástico da Ordem de Cristo ao longo da primeira metade do século XIV nas comendas de Ega, Soure, Redinha e Pombal. ${ }^{8}$

\footnotetext{
4 Texto completo disponível- http://www.historia.uff.br/stricto/teses/Tese-2007_BERRIEL_Marcelo_ Santiago-S.pdf.

5 José Rivair de Macedo (org.). Os Estudos Medievais no Brasil, p. 35.

6 José Rivair de Macedo (org.). Os Estudos Medievais no Brasil, p. 41.

7 Referência e resumo disponível em: http://www.historia.uff.br/stricto/tesesdata.php.

8 Referência e resumo disponível em: http://www.ppghis.ifcs.ufrj.br/cgi/cgilua.exe/sys/start.htm.
} 
Ferreira, Roberto Godofredo Fabri. O Tempo Novo e a Origem dos Novos Tempos - A Construção do Tempo e da Temporalidade nos Primórdios da Dinastia de Avis (1370 a 1440). Estudo realizado no Setor Temático de História Medieval. No referido trabalho o autor estudou a ordenação do tempo e da temporalidade em Portugal, onde ambos, sob influência régia marcante, foram ordenados e difundidos na sociedade portuguesa, notadamente nos meios urbanos. ${ }^{9}$

Gimenez, José Carlos. A rainha Isabel nas estratégias políticas da Península Ibérica (1280-1336). Apoiando-se em um corpus documental formado por cartas, crônicas, bulas e testamentos, esta tese discute a participação da Rainha Isabel de Portugal (1270-1336) nas estratégias políticas da Península Ibérica na Baixa Idade Média. ${ }^{10}$

Gonçalves, Beatris dos Santos. Os Marginais e o Rei. A Construção de uma estratégica relação de poder em fins da Idade Média portuguesa. Estudo sobre a atuação política dos reis de Avis, de D. Duarte a D. Manuel I cujo objetivo era o fortalecimento e centralização do poder monárquico. A partir dos conceitos de centralidade e marginalidade, baseado, dentro outros teóricos, nas noções de Bronislaw Geremek, analisou-se a ação da justiça régia por meio de fontes normativas, arquivísticas e cronísticas, concluindo-se que a marginalidade era definida e redefinida, segundo os interesses monárquicos, constituindo-se numa das mais importantes estratégias régias. ${ }^{11}$

Guimarães, Marcella Lopes. Estudo de representações de monarca nas crônicas de Fernão Lopes (séculos XIV e XV) - O espelho do Rei: Decifra-me $e$ te devoro. A autora sustenta a hipótese que o afastamento do cronista Fernão Lopes pode estar ligado à recepção das suas representações de monarca, levadas a efeito pela geração do rei D. Afonso V. Assim, ela analisa as representações de monarca construídas nas crônicas de Fernão Lopes (1385 - 1460), a saber: a Crônica de D. Pedro, a Crônica de D. Fernando e a Crônica de D. João I. ${ }^{12}$

\footnotetext{
9 Referência e resumo disponível em: http://www.historia.uff.br/stricto/tesesdata.php.

10 Texto completo disponível na URL: http://dspace.c3sl.ufpr.br/dspace/handle/1884/6039.

11 Texto completo disponível na URL: http://www.historia.uff.br/stricto/td/1238.pdf.

12 Texto completo disponível: http://www.poshistoria.ufpr.br/documentos/2004/Marcellalopesguimaraes. pdf.
} 
Lachi, Antônio Luiz. D. Dinis, o Pai da Pátria de Portugal: a formação de uma imagem, as realizações político-diplomáticas e suas repercussões. Nesta tese, o autor observou as realizações políticas e administrativas do reinado de D. Dinis, bem como a resolução das crises internas e o desenvolver do sentimento nacional lusitano, destacando, principalmente, a construção da imagem deste rei português. ${ }^{13}$

Mendes, Lenora Pinto. A Música no Teatro de Gil Vicente: A função do espetáculo no projeto político da Dinastia de Avis (? 1465-1536). Este é um estudo realizado no Setor Temático de História Medieval, Baixa Idade Média (séculos XIV e XV), no qual a autora analisou a função da música como elemento de elevada importância no teatro vicentino, integrando um conjunto discursivo - o discurso do paço - para a produção e veiculação da imagem do rei e do reino português sob a Dinastia de Avis. As músicas analisadas têm textos provenientes de cancioneiros portugueses e espanhóis. ${ }^{14}$

Nascimento, Denise da Silva Menezes do. O poder negociado: os crimes contra a pessoa e sua honra no reinado de D. João II. Denise Nascimento desenvolveu seu trabalho sobre a concessão de perdão para os crimes contra a pessoa e sua honra durante o reinado de D. João II (1481-1495). A autora apontou que, muito embora fosse uma prerrogativa do rei, que evidenciava a pretensão do poder régio em tutelar outros poderes, este ato gracioso implicava, fundamentalmente, numa negociação entre o monarca e seus súditos. ${ }^{15}$

Nascimento, Renata Cristina de Sousa. Os privilégios e os abusos da nobreza em um período de transição: o reinado de D. Afonso V em Portugal (1448-1481). A autora analisa os privilégios e os abusos da nobreza no governo de D. Afonso V, rei de Portugal durante os anos de 1448 a 1481. A documentação base para a análise foram as Cortes realizadas durante os anos de 1451 a $1478 \mathrm{e}$ as Ordenações Afonsinas. Tese desenvolvida junto à linha de pesquisa Cultura e Poder. ${ }^{16}$

${ }^{13}$ José Rivair de Macedo (org.). Os Estudos Medievais no Brasil, p. 71.

${ }^{14}$ Referência e resumo disponível em: http://www.historia.uff.br/stricto/tesesdata.php.

${ }_{15}$ Texto completo disponível em: http://www.teses.usp.br/teses/disponiveis/8/8138/tde-03022010$163806 /$.

16 Texto completo disponível - http://www.poshistoria.ufpr.br/documentos/2005/RenataCristinade sousanascimento.pdf. 
SAla, Edna. A imagem feminina no espelho medieval e seu reflexo nas cantigas de escárnio e maldizer. Nesta investigação, a autora analisou a construção da imagem feminina na Idade Média Ibérica e seu reflexo nas cantigas de escárnio e maldizer produzidas entre os séculos XII e XIV. ${ }^{17}$

SANTos, Dulce Oliveira Amarante dos. O corpo dos pecados: representações e práticas sócio-culturais femininas nos reinos ibéricos de Leão, Castela e Portugal (1250-1350). O autor buscou estudar as proposta de doutrinação da sociedade pela Igreja, dando atenção a análise de vários elementos que serviram de referência à construção das representações corporais do masculino, dos pecados do corpo e do feminino. ${ }^{18}$

Santos, Maria do Carmo Parente. O poder feminino na Península Ibérica da Reconquista. A partir da análise das crônicas produzidas na Península Ibérica, a autora reflete sobre a posição das rainhas e seu papel político nos reinos ibéricos durante a Reconquista. ${ }^{19}$

Selles, Marcio Paes. Entre a Corte e a Capela: o espetáculo como legitimação de poder e propaganda na Dinastia de Avis (1385-1574). Realizada no Setor Temático de História Medieval, Baixa Idade Média (séculos XIV e XV), nesta pesquisa se analisou a utilização de diferentes manifestações musicais em diversas cerimônias régias que visavam à legitimação e à consolidação do poder régio. As fontes utilizadas foram algumas crônicas do período, os cancioneiros poéticos e musicais, os tratados de música e os manuais de comportamento cortesão. $^{20}$

Silva, Gerson Gonçalves da. Amor, caritas e razão: sustentáculos de um velho mundo medieval - Tratado da Virtuosa Benfeitoria, do Infante D. Pedro. Nesta análise do livro Tratado da Virtuosa Benfeitoria, o autor considera os conceitos de amor, caritas e razão como a tríade que serve de sustentáculo à ideologia sobre o direito divino do poder real, justificando a rígida hierarquia feudal com respaldo na religião. ${ }^{21}$

\footnotetext{
17 José Rivair de Macedo (org.). Os Estudos Medievais no Brasil, p. 108.

18 José Rivair de Macedo (org.). Os Estudos Medievais no Brasil, p. 111; http://www.historia.uff.br/ stricto/tesesdata.php

19 José Rivair de Macedo (org.). Os Estudos Medievais no Brasil, p. 112.

${ }^{20}$ Referência e resumo disponível em: http://www.historia.uff.br/stricto/tesesdata.php.

21 José Rivair de Macedo (org.). Os Estudos Medievais no Brasil, pp. 113-114.
} 
Zierer, Adriana Maria de Souza. Paraíso, Escatologia e Messianismo em Portugal à Época de D. João I. Nesta tese, a autora trata da incorporação dos relatos de viagens imaginárias no Além (Purgatório, Inferno e Paraíso) ao universo mental português com a difusão de narrativas referentes ao Paraíso terreal. Desta forma, aborda a relação entre construção de um topos imaginário associado à afirmação da Dinastia de Avis no contexto da crise do feudalismo. ${ }^{22}$ 


\section{Nota Final: Fontes de Informação e Siglas}

As referências foram retiradas dos sites dos núcleos de pesquisa, dos sites dos Programas de Pós-Graduação em História e/ou dos sites das Bibliotecas Digitais das seguintes instituições: UFF (Banco de Dissertações e Teses da UFF na URL: http://www.historia.uff.br/stricto/tesesdata.php); UFRJ (Banco de Dissertações e Teses de 1999 até 2005 da UFRJ na URL: http://www.ppghis. ifcs.ufrj.br/cgi/cgilua.exe/sys/start.htm; http://www.hcomparada.ifcs.ufrj.br/ dissertacoes/index.php\#); USP (Biblioteca Digital da USP na URL: http:// www.teses.usp.br/); UNESP/Franca (Banco de Dissertações e Teses de 1983 até 2010 da UNESP (Franca) na URL: http://www.franca.unesp.br/poshistoria/ interno-poshisMenuDisdissert.php; http://200.145.119.5/poshistoria/internoposhisTeses.php); UFRGS (Banco de Dissertações e Teses de 1990 até 2010 da UFRGS na URL: http://www.ufrgs.br/ppghist/dissertacoes.asp; http:// www.ufrgs.br/ppghist/teses.asp); UFPR (para mais trabalhos realizados na UFPR, conferir: http://www.poshistoria.ufpr.br/bancoteses.htm). Foram ainda utilizados: Almeida, Ana Carolina e Amaral, Clínio, «O Ocidente Medieval segundo a historiografia brasileira», Medievalista online, ano 4, n.4, p.1-41, 2008, e José Rivair de Macedo (org.), Os estudos medievais no Brasil. Catálogo de dissertações e teses - Filosofia, História e Letras (1990-2002), Porto Alegre: EDUFRGS, 2003 (disponível online no site da ABREM).

\section{Siglas}

\section{Professores orientadores}

CAI - Carlos A. Iannone

CAV - Carlos A. Vecchi

CB - Carla Brandalise

CRFN - Carlos Roberto Figueiredo Nogueira

FC - Flávio de Campos

FJG - Francisco José Gomes

FRF - Fátima Regina Fernandes

GA - Gracilda Alves

GPN - Guilherme Paulo Castagnoli Pereira das Neves

HO - Haquira Osakabe

IMD - Ivone Marques Dias

JBN - Jonatas Batista Neto

JRM - José Rivair de Macedo 
JRS - José António de Camargo Rodrigues de Sousa

MCC - Marilda C. Ciribelli

MEGV - M ${ }^{\mathrm{a}}$ Elisabette G. de Vasconcelos

MJMB - Mário Jorge da Motta Bastos

MLG - Marcela Lopes Guimarães

MSG - M $\mathrm{M}^{\mathrm{a}}$ Sonsoles Guerra

RGFF - Roberto Godofredo Fabri Ferreira

SCG - Simone Caputo Gomes

SF - Suely Flori

SG - Sidinei Galli

SSLF - Susani Silveira Lemos França

TO - Teresinha Oliveira

VDS - Victor Deodato da Silva

VLF - Vânia L de Froes

\section{Universidades}

PUCRJ - U. Católica Rio Janeiro

UEM - U. Estatal de Maringá

UFF - U. Federal Fluminense

UFG - U. Federal Goiás

UFPR - U. Federal Paraná

UFRGS - U. Federal Rio Grande Sul

UFRJ - U. Federal Rio de Janeiro

UNESP - U. Estadual Paulista

UNICAMP - U. Estadual de campinas

USP - U. São Paulo 
